ANDRÉ DE SOUZA MELO

Identificação de pontos quentes em transformadores de potência por meio de técnicas não invasivas 


\section{Identificação de pontos quentes em transformadores de potência por meio de técnicas não invasivas}

Dissertação de Mestrado apresentada à Escola Politécnica da Universidade de São Paulo para obtenção do título de Mestre em Ciências pelo Programa de Pós-graduação em Engenharia Elétrica

Área de Concentração: Sistemas de Potência

Orientador: Prof. Dr. Eduardo Coelho Marques da Costa Co-orientador: Prof. Dr. Silvio Giuseppe Di Santo

São Paulo

2017 

Este exemplar foi revisado e corrigido em relação à versão original, sob responsabilidade única do autor e com a anuência de seu orientador.

São Paulo, de de

Assinatura do autor:

Assinatura do orientador:

Catalogação-na-publicação

Melo, André de Souza

Identificação de pontos quentes em transformadores de potência por

meio de técnicas não invasivas / A. S. Melo -- versão corr. -- São Paulo, 2017. $70 \mathrm{p}$.

Dissertação (Mestrado) - Escola Politécnica da Universidade de São Paulo. Departamento de Engenharia de Energia e Automação Elétricas.

1.TRANSFORMADORES E REATORES 2.MÉTODO DOS ELEMENTOS FINITOS 3.GASES I.Universidade de São Paulo. Escola Politécnica.

Departamento de Engenharia de Energia e Automação Elétricas II.t. 


\section{Agradecimentos}

Ao Autor da Vida: Jesus Cristo por nos conceder inteligência, saúde, família, pessoas queridas em nosso caminho e a oportunidade de agradecer parentes e amigos.

À minha amada esposa Andreza pelo grande apoio, incentivo, paciência, carinho e compreensão durante todas as fases deste trabalho.

Aos meus pais Manoel e Linda pelo apoio, incentivo e compreensão fundamentais durante toda minha formação acadêmica.

Á minha irmã Adriana que está sempre disposta e pronta a ajudar e incentivar. Aos Professores Dr. Silvio e Dr. Eduardo pelo fundamental apoio, orientação e grande ajuda na elaboração deste trabalho.

Ao professor Dr. Plínio pelo incentivo, ajuda e confiança.

Aos amigos da ABB, principalmente: Wilerson, Paulo, Zacharias e Thomas pela motivação, pela compreensão, incentivo e discussões técnicas.

Aos demais amigos que direta ou indiretamente fizeram parte deste trabalho 


\title{
Resumo
}

\author{
MELO, A. S. Identificação de pontos quentes em transformadores de potência por meio \\ de técnicas não invasivas.
}

Esta pesquisa apresenta uma metodologia, baseada em duas técnicas não invasivas para identificação e diagnóstico de pontos quentes em transformadores de potência durante plena operação ou em fase de projeto. A primeira técnica é baseada na medição de radiação infravermelha, emitida pelo equipamento em funcionamento e registrada por meio de análise termográfica. A segunda técnica é possível a partir do conhecimento prévio das características construtivas do transformador, fazendo uso do Método dos Elementos Finitos (MEF). A segunda técnica pode ser validada a partir das medições realizadas utilizando a primeira técnica. A formação de gases no interior dos transformadores de potência, devido à elevação da temperatura do óleo isolante em função dos pontos quentes, é discutida em detalhes com base nas normas técnicas estabelecidas pelo IEEE e IEC. As técnicas e procedimentos abordados ao longo dessa pesquisa foram obtidos a partir de um transformador com potência nominal de 120 MVA e relação de tensão $13,8 / 230 \mathrm{kV}$, projetado para integrar uma fazenda eólica ao Sistema Interligado Nacional (SIN).

Palavras-chave: transformadores de potência; pontos quentes, óleo isolante; coordenação de isolamento; Método dos Elementos Finitos, geração de gases. 


\begin{abstract}
MELO, A. S. Identification of hot spots in power transformers using noninvasive techniques.

This research presents a methodology based on two noninvasive techniques for identification and diagnostic of hot spots in power transformers during operation or project development. The first is based on measurements of infrared radiation from the equipment during operation and recording by thermography. The second technique is possible from the previous knowing of the constructive characteristics of the power transformer, by using the Finite Element Method (FEM). The second technique can be validated from measurements obtained using the first technique. The gas formation into the power transformers, because of the high temperatures in the insulating oil due to the hot spots, is discussed in details based on normative recommendations well established by the IEEE and IEC. All techniques and procedures to be approached in this research were obtained using a 120-MVA power transformer with voltage relationship of $13.8 / 230 \mathrm{kV}$ that was projected to interconnect a wind farm to the Interconnected Brazilian System (Sistema Interligado Nacional - SIN).
\end{abstract}

Keywords: power transformer; hot spots; insulating oil; insulation coordination; Finite Elements Method, DGA. 


\section{Lista de figuras}

Figura 1 - Pressões parciais de equilíbrio térmico de Halstead em função da temperatura..... 20

Figura 2 - Identificação de falhas em função da proporção relativa de gases. .........................22

Figura 3 - Concentração dos gases em função da temperatura...............................................24

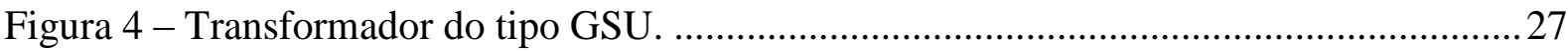

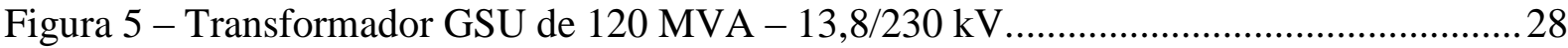

Figura 6 - Bucha de baixa tensão fixada sobre o caneco e transformador de corrente.............30

Figura 7 - Conservador de óleo (tanque de expansão)........................................................ 31

Figura 8 - Bolsa de borracha utilizada no interior do conservador de óleo............................. 32

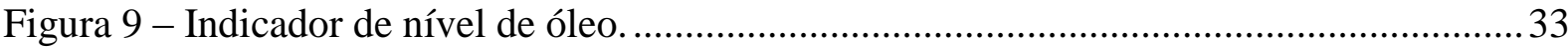

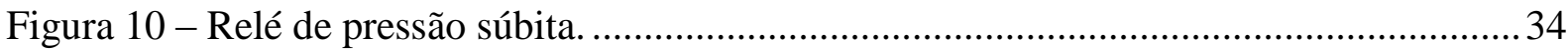

Figura 11 - Relés para detecção de gases do tipo Buchholz................................................... 35

Figura 12 - Ilustração do custo de uma falha versus etapa que se encontra o produto.............39

Figura 13 - Vista radial do flange de baixa tensão e condutor do transformador. ....................41

Figura 14 - Região de solução discretizada em partes menores com formas conhecidas........ 46

Figura 15 - (a) Reta com dois nós (casos 1D). (b) Triângulo com três nós. (c) Retângulo com quatro nós. (d) Tetraedro com quatro nós (casos 3D). ........................................ 46

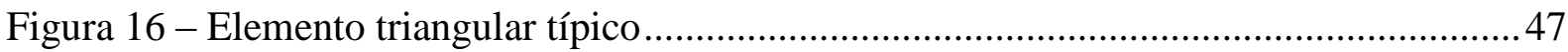

Figura 17 - Planta de tratamento de óleo (desgaseificação e filtragem). ................................51

Figura 18 - Modelo em CAD do tanque, flange e condutores. ..............................................55

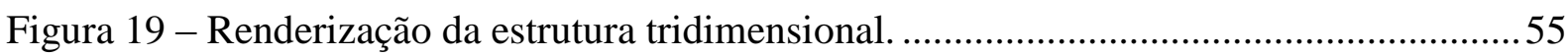

Figura 20 - Termovisão lado esquerdo (bucha inclinada $\mathrm{H} 1$ e central H2) ............................57

Figura 21 - Termovisão do lado direito (bucha inclinada H3 e central H2)...........................57

Figura 22 - Perfil de temperatura calculado por meio do MEF. ............................................59

Figura 23 - Perfil de temperatura calculado por meio do MEF após o reparo. ........................61

Figura 24 - Termovisão da parte superior do transformador após o reparo............................. 62 


\section{Lista de tabelas}

Tabela 1 - Diagnóstico pelo Método do Gás Chave. ............................................................ 25

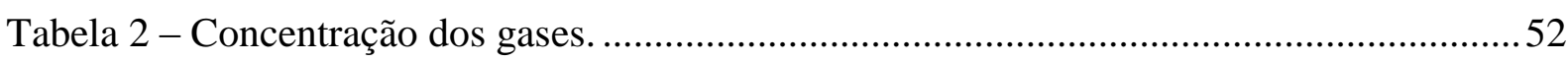

Tabela 4 - Cálculo e medição da temperatura nos pontos quentes .........................................60

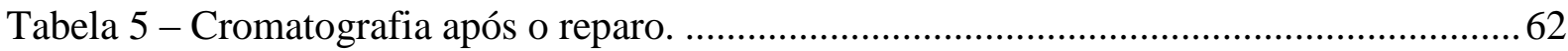

Tabela 6 - Evolução na formação de gases após o reparo. ...................................................63 


\section{Sumário}

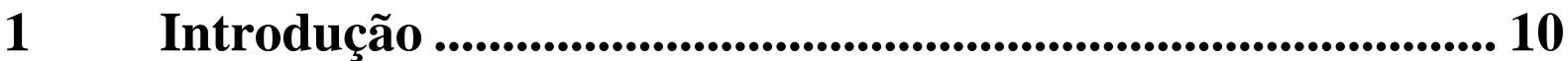

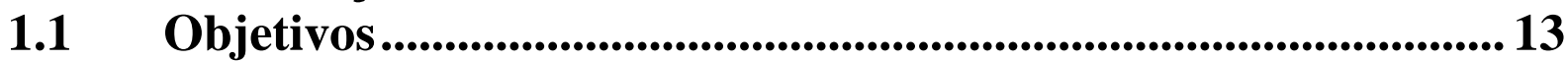

1.2 Organização do trabalho ................................................................... 14

2 Gases no interior de transformadores ................................. 16

2.1 Detecção de gases no óleo mineral ................................................... 16

2.2 Formação de gases no interior de transformadores..................... 18

2.3 Análise e interpretação dos gases..................................................... 21

3 Transformadores de potência...................................................... 26

3.1 Bucha de porcelana e canecos de fixação ...................................... 28

3.2 Conservador de óleo .....................................................................30

3.3 Medição do nível e da temperatura do óleo ……………………......32

3.4 Controle da pressão no interior dos transformadores................ 34

3.5 Relé de deteç̧ão de gases ..................................................................... 35

3.6 Outros componentes de transformadores de potência ................36

4 Cálculo e medição da temperatura nos pontos quentes..... 37

4.1 Introdução ............................................................................................37

4.2 Passos no desenvolvimento de um transformador ...................... 38

4.3 Cálculo analítico da temperatura nos pontos quentes ................ 40

4.4 Método dos Elementos Finitos MEF.............................................. 45

4.4.1 Discretização da região em elementos................................................... 45

4.4.2 Equações governantes dos elementos ......................................................47

4.4.3 Junçã̃o dos elementos.................................................................................. 48

4.4.4 Solução do sistema de equações .............................................................49

4.5 Detecção e análise dos gases.............................................................. 49

4.6 Cálculo da temperatura utilizando MEF .......................................5 54

4.7 Análise termográfica do transformador .........................................56

4.8 Análise térmica pelo MEF e método analítico...............................58

4.9 Análise térmica e dos gases após o reparo ..................................... 61

5 Recomendações para especificações, projetos, operação e análise de transformadores....................................................... 64

6 Conclusão....................................................................................... 65

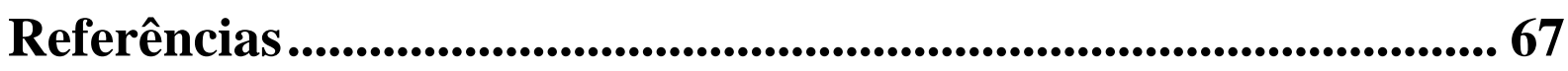




\section{Introdução}

É na Inglaterra em 1883 que começa a história dos transformadores quando Lucien $\mathrm{H}$. Gawlard e John G. Gibbs os incorporaram a um sistema de iluminação um dispositivo chamado de gerador secundário. Eram duas bobinas longas e cilíndricas uma ligada à carga, outra ligada ao gerador e dentro das bobinas um núcleo magnético móvel construído com fios de ferro. Na realidade este dispositivo mais se assemelhava a um indutor com núcleo variável.

Contudo, foi em Budapeste, Hungria onde as empresas Ganz, em 1885, patentearam o que se pode entender como a transição do indutor variável de Gibbs para versões rudimentares, contudo mais eficientes, dos conceitos de transformadores Core Type e Shell Type. Na mesma época, nos Estados Unidos, William Stanley e George Westinghouse também introduziram o transformador em Great Barrington (JESZENSZKY S. 1996).

Neste contexto, ao longo da história, as principais contribuições devem-se aos seguintes cientistas:

- Coulomb, século XVIII

- Ampere, 1774 a 1835

- Oersted, 1776 a 1852

- Faraday, 1792 a 1866

- Lenz, 1813 a 1864

- Joule, 1816 a 1888

- Maxwell, 1830 a 1880

A energia elétrica não pode ser diretamente utilizada. Ela deve ser transformada através de transdutores chamados máquinas elétricas, as quais fazem a transformação de forma dinâmica, por exemplo energia elétrica em energia mecânica (Motores), mecânica em elétrica (Geradores) ou de forma estática. Transformadores são máquinas elétricas estáticas que se destinam basicamente a transformar a energia elétrica em alta corrente e baixa tensão em energia elétrica com alta tensão e baixa corrente, ou vice-versa - Tudo isto com reduzida perda de energia durante a transformação. Eles são amplamente utilizados em sistemas elétricos que se estendem desde aplicações em sistemas eletrônicos a grandes sistemas de geração e transmissão de energia elétrica, caracterizados por níveis de tensão na ordem de centenas de kVs. Além disso, os transformadores são equipamentos utilizados tanto na transformação da energia elétrica quanto no monitoramento/medição de sistemas elétricos em geral (MENDES,1987). 
Os atuais sistemas de transmissão e geração em corrente alternada, que representam a base do setor elétrico mundial, foram possíveis devido ao advento dos precursores dos atuais transformadores de potência na primeira metade do século XIX. No entanto, vale ressaltar que o principio de funcionamento dos transformadores modernos é o mesmo de seus precursores há aproximadamente 150 anos, baseando-se na Lei de Faraday e na terceira equação de Maxwell (FITZGERALD, 2003). As principais alterações, realizadas em grande parte ao longo dos últimos cinquenta anos, são associadas à isolação elétrica interna desses equipamentos e à eficiência na transformação. $O$ aprimoramento no projeto do núcleo ferromagnético, condutores dos enrolamentos, isolação elétrica interna (por meio de papel Kraft e óleo) e técnicas para evitar sobreaquecimento interno, são alguns dos principais avanços no projeto de transformadores de potência nas últimas décadas.

No que diz respeito ao aumento da eficiência da transformação da energia, o maior avanço está na utilização de materiais ferromagnéticos com maior permeabilidade magnética, na laminação do núcleo por meio de finas chapas de aço silício de grãos orientados, recobertas por uma película isolante resistente ao calor, com o objetivo de minimizar as perdas térmicas devido às correntes parasitas e, consequentemente, obter maior eficiência na transformação da energia elétrica. Outro fator importante é o projeto da seção transversal do núcleo ferromagnético, visando uma relação ótima de custo/benefício em função da finalidade e da zona de saturação magnética do equipamento (curva de histerese).

Além das alterações realizadas na parte ativa dos transformadores de potência, núcleo ferromagnético e enrolamentos, a isolação elétrica interna e resfriamento dos transformadores de potência sofreram significativas modificações ao longo das últimas décadas, seja por motivos associados ao desempenho operacional desses equipamentos ou exigências de cunho ambiental. A grande maioria dos transformadores de potência, utilizados tanto nas redes de distribuição quanto de transmissão de energia elétrica, são internamente isolados com óleo mineral e, mais recentemente, fazendo uso de óleo vegetal (biodegradável). O óleo que preenche o espaço entre o tanque aterrado e a parte ativa dos transformadores (núcleo e enrolamentos) atua como dielétrico ou extintor de arco elétrico (descargas parciais) e também como dissipador de calor entre a parte ativa e o meio ambiente. Atualmente, transformadores de alta potência, na faixa de 500MVA chegam a apresentar rendimentos de até $99.8 \%$ (CALIL, 2009). Além disso, reduções de massa e materiais chegam a 35\% comparados aos projetos da década de 70 .

Do ponto de vista operacional, a função do óleo como isolante elétrico e como dissipador de calor é óbvia: manter o equipamento operando de forma nominal e sem 
interrupções. No entanto, caso existam descargas parciais, arcos elétricos no interior do equipamento e grandes variações na temperatura, a degradação da isolação elétrica pode ocorrer de forma mais pronunciada tanto do óleo quanto da celulose utilizada na isolação dos enrolamentos e conexões internas (LARS et al., 2004). Na maioria dos casos, altas temperaturas no óleo dos transformadores de potências são resultantes da operação inadequada do equipamento (sobrecarga), recorrentes descargas parciais, corona, arcos elétricos e também existência de pontos quentes oriundos do subdimensionamento de componentes no interior do transformador; ou então da existência de peças compostas por material ferromagnético fora do núcleo ativo e sujeitos a altos campos magnéticos, resultando no sobreaquecimento dessas peças devido ao surgimento de correntes parasitas induzidas pelo fluxo de dispersão. Além disso, existem situações anormais onde o óleo do OLTC, que é sujeito a arcos e descargas, entra em contato com o óleo principal do transformador contaminando-o e acelerando a degradação (SOUZA et al., 2016; SOUZA E CALIL, 2014; FERREIRA, 2013).

As grandes variações na temperatura do óleo isolante ocorrem principalmente devido às descargas parciais e à existência de pontos quentes no interior dos transformadores. A variação na temperatura do óleo implica na formação de diversos tipos de gases, alguns deles devido às falhas na isolação solida dos transformadores (celulose) e outros devido a descargas disruptivas através do óleo no interior do tanque desses equipamentos. Gases formados a partir de falhas elétricas no óleo dos transformadores apresentam características combustíveis, tais como o $\mathrm{H}_{2}$ e $\mathrm{C}_{2} \mathrm{H}_{2}$. Esses gases são formados em um ponto denominado na literatura técnica como ponto de fulgor e podem ser combustíveis ou não, dependendo muito do tipo de falta e em onde ocorrem (óleo, celulose ou ambos). A formação de gases combustíveis podem representar grandes riscos na operação do sistema e na integridade física de recursos humanos responsáveis pela manutenção desses equipamentos (IEEE, 2008).

$\mathrm{Na}$ detecção de partes quentes e projeto de transformadores de potência em geral, duas técnicas não invasivas serão estudadas e comparadas ao longo deste trabalho: diagnóstico por análise termográfica e por meio do Método dos Elementos Finitos (MEF) (CARDOSO, 2016). A primeira técnica trata-se de um método in loco, podendo ser aplicada em equipamentos em campo, sendo os pontos quentes identificados por meio da medição da radiação infravermelha emitida pelo transformador. Por outro lado, o segundo método trata-se de uma ferramenta amplamente utilizada durante a fase de projeto do equipamento, fazendo uso de recursos computacionais e prévio conhecimento das características construtivas do transformador. 


\subsection{Objetivos}

A pesquisa foi desenvolvida a partir do projeto de um transformador com potência nominal 120 MVA, relação de tensão 34,5/230 kV, desenvolvido nos laboratórios de um fabricante mundialmente conhecido no setor elétrico. O equipamento foi projetado dentro de todos os requisitos de projeto definidos nas especificações, normas técnicas e processos de qualidade estabelecidos. Contudo ele apresentou uma geração de gases não previstos, mostrando a presença de alguma possível anomalia interna que posteriormente foi detectada como uma troca indevida de materiais montados nas partes estruturais externas à parte ativa. Este transformador, construído para fins comerciais apresentou pontos quentes não esperados na etapa de projeto, os quais que foram identificados a partir de termografia por radiação infravermelha e posteriormente validada por meio de cálculos utilizando Método dos Elementos Finitos (MEF). Além do MEF, uma formulação analítica foi elaborada unindo os campos do eletromagnetismo e da termodinâmica (VECHIO R.M et al 2009; INCROPERA F.P, 2007) A hipótese da existência de pontos quentes no interior do equipamento foi levantada devido à formação de alguns gases combustíveis no óleo mineral, que representa uma espécie de assinatura físico-química da existência desse tipo de defeito.

Frente o exposto, o objetivo deste projeto de pesquisa é discutir o problema dos pontos quentes de transformadores de potência, propor técnicas para soluciona-lo (fazendo uso de medições e técnicas computacionais) e alertar sobre possíveis falhas no processo de fabricação em equipamentos da mesma classe de tensão, criando-se, então uma metodologia de análise para se diagnosticar e solucionar o defeito. Portanto, os objetivos desta dissertação podem ser enumerados da seguinte forma:

- Discussão acerca dos principais gases formados no interior de transformadores de potência em função do aumento da temperatura durante a operação, devido à sobrecarga na operação, descargas parciais, arco elétrico, corona ou existência de pontos quentes (problemas de fabricação ou projeto);

- Identificação e medição da temperatura dos pontos quentes imersos no óleo mineral, por meio de termografia por radiação infravermelha;

- Validação das medições realizadas por meio de termografia, fazendo uso do MEF, conhecendo-se previamente as características construtivas do equipamento; 
- Proposta de alterações no projeto do transformador no início da concepção, com o âmbito de se eliminar os pontos quentes e consequentemente resolver o problema da degradação precoce da isolação elétrica no interior do equipamento.

- Entende-se por métodos invasivos de reparo a reconstrução dos enrolamentos e substituição de centenas de milhares de litros de óleo no caso de grandes transformadores

\subsection{Organização do trabalho}

O presente documento está dividido em seis seções. Esta primeira seção apresenta os objetivos e organização do trabalho proposto, bem como uma breve introdução e informações básicas acerca da motivação da pesquisa.

O segundo capítulo aborda a dinâmica de formação de gases no interior de transformadores de potência devido ao sobreaquecimento, seja por sobrecarga na operação, descargas parciais ou falhas na construção e concepção do equipamento (e.g. pontos quentes). São descritos os diversos tipos de gases que se formam ao longo de uma dada faixa de temperaturas na qual o óleo dos transformadores de potência é submetido devido aos eventuais pontos quentes e descargas parciais. Grande parte das informações apresentadas no segundo capítulo tem como base o IEEE Guide for the Interpretation of Gases, reconhecido como documento normativo pelo American National Standards Institute (ANSI) (IEEE, 2008).

O terceiro capítulo apresenta uma revisão acerca dos transformadores de transmissão de energia elétrica (Generator Step-Up Transformers - GSU), bem como a definição apresentada pela literatura técnica sobre o equipamento estudado e aspectos históricos.

O quarto capítulo dedica-se à introdução do MEF, utilizado como uma das técnicas abordadas para detecção dos pontos quentes em transformadores de potência em operação ou em fase de desenvolvimento. Além de uma abordagem analítica coma finalidade de prover melhor sensibilidade quantitativa dos fenômenos.

O quarto capítulo também mostra resultados obtidos por meio de análise termográfica realizada após a detecção de gases no equipamento durante testes laboratoriais. Nesse mesmo capítulo, os dados obtidos de forma experimental são comparados aos resultados obtidos de forma analítica e fazendo-se uso do MEF. As eventuais causas da existência de pontos 
quentes em transformadores são discutidas, bem como a abordagem adotada para o caso analisado em particular.

Por fim, o quinto e o sexto capítulos apresentam conclusões sobre as técnicas utilizadas na detecção de pontos quentes, meios para aperfeiçoar o projeto de transformadores de potência da mesma classe do equipamento analisado, peculiaridades no desenvolvimento de transformadores de potência e eventuais falhas durante o processo de fabricação desses equipamentos. 


\section{Gases no interior de transformadores}

A problemática acerca dos pontos quentes em transformadores de potencia deve ser abordada em conjunto com a teoria e normas técnicas sobre a dinâmica de formação de gases em função da temperatura de operação e de eventuais falhas de origem térmica ou elétrica. Neste contexto, torna-se necessário a introdução sobre quais são os possíveis gases que se formam no interior desses equipamentos, dissolvidos no óleo mineral, bem como a faixa de temperatura em que cada gás é produzido.

A norma técnica detalha a dinâmica da formação de cada gás em função da pressão e temperatura do óleo no interior de transformadores, métodos de detecção, medição e interpretação dos resultados obtidos de forma experimental durante a operação em campo ou durante ensaios laboratoriais (IEEE, 2008; IEC, 1999; ASTM, 2002).

\subsection{Detecção de gases no óleo mineral}

A maior parte da literatura técnica (IEEE, 2008; IEC60599, 2009; PERRIER (2009); HUANG 2013, MARTINS A.C, 2014, FERREIRA 2011) dedicada à detecção e identificação de gases, tratamento do óleo isolante e confiabilidade dos dispositivos e acessórios de transformadores, é aplicada aos transformadores preenchidos com óleo mineral. Dessa forma, a análise realizada ao longo deste trabalho aborda transformadores com óleo mineral e não aqueles preenchidos com óleo vegetal, geralmente utilizados na rede de distribuição de energia elétrica.

A detecção de certos tipos de gases no interior de transformadores, imersos no óleo isolante, é um dos primeiros indicadores de mau funcionamento nesses equipamentos de alto valor agregado, resultando em falhas e interrupção no fornecimento de energia elétrica. Falhas resultantes de gases no interior de transformadores podem ocorrer de maneira isolada ou mesmo associada a outros fatores, tal como a deterioração da isolação dos transformadores (celulose e óleo), associada à formação progressiva de gases combustíveis, o que em alguns casos pode resultar em explosão e danos materiais e de recursos humanos. De modo geral, a formação de gases no interior desses equipamentos é resultante da operação inadequada (sobrecarga), efeito corona, descargas parciais e arcos elétricos através do óleo isolante, entre outros fenômenos eletrostáticos que levam ao sobreaquecimento do óleo. No entanto, grandes variações na temperatura podem ser também ocasionadas por eventuais falhas no projeto dos 
transformadores de potência. Um exemplo de falha recorrente no projeto de transformadores é a presença de peças ferromagnéticas externas ao núcleo dos enrolamentos e sujeitas a altos fluxos magnéticos dispersos, imersas no óleo isolante, que também funciona como dissipador térmico. Tais peças são aquecidas devido à presença de correntes parasitas em função do fluxo magnético de dispersão, gerado também pelos enrolamentos do transformador (PREVOST, 2005).

Embora diversas técnicas para detecção e diagnóstico de gases no interior de transformadores são estabelecidas na literatura técnica, a análise desses gases e interpretação das possíveis falhas na operação e de projeto do equipamento, mostra-se como um procedimento quase que artesanal e não como uma ciência exata propriamente dita (GERTH, 2017). Muitas vezes são necessárias diversas técnicas e procedimentos para detecção e classificação desses gases, envolvendo técnicas bem estabelecidas (relés de formação de gases em transformadores) e em desenvolvimento (medição por cromatografia e fazendo-se o uso de métodos heurísticos de análise) (ZIRBES et al., 2005; ARANTES, 2005). Por fim, como requisito importante para correto diagnóstico de falhas e previsão de possíveis problemas em transformadores de potência, a partir da detecção de gases, combustíveis ou não, é essencial a habilidade e experiência técnica na análise dos resultados obtidos.

A American Society for Testing and Materials (ASTM) é um órgão norte americano de normalização. Os resultados de vários procedimentos de testes da ASTM, para detecção e análises de gases em transformadores, mostram que conclusões sobre tais resultados eram difíceis, apresentavam pouca precisão e podiam conter diversas imprecisões entre laboratórios (IEEE, 2008). Atualmente, técnicas avançadas na detecção de pontos quentes e detecção/identificação de gases, tornaram o processo em questão mais confiável. Neste trabalho procura-se tratar da detecção dos pontos quentes em transformadores e identificação dos gases gerados em função do aumento da temperatura, baseando-se nas normas técnicas estabelecidas pelo IEEE, IEC e ASTM (IEEE, 2008; IEC 60599 (2009); ASTM, 2002) de forma a contribuir com que já é exposto e proposto nas mesmas acrescentando experiência oriunda da indústria.

O guia para análise de gases do IEEE apresenta sugestões para métodos específicos e procedimentos para operação de transformadores com a presença de gases combustíveis no interior do tanque. As informações contidas nesse guia são em grande parte dados obtidos de forma experimental e que podem variar de acordo com as características técnicas e construtivas de cada transformador, tais como: tipo de óleo, método de coleta de amostragens, 
método de medição, técnicas de refrigeração do óleo, entre várias outras características e tipos de procedimentos para realização das análises (IEEE, 2008).

Atualmente, o método mais utilizado no monitoramento de transformadores de potência é baseado na simples determinação do total de gases combustíveis no óleo, Total Combustible Gases (TCG) e fundamentado nas descrições normativas da International Electrotechnical Commission (IEC) (IEC, 1999). Essa técnica de monitoramento/manutenção é prática, simples e pode ser aplicada em campo a partir da coleta de amostras do óleo dos transformadores em operação. No entanto, esse método não é capaz de detectar outros gases não combustíveis, tais como os óxidos de carbono. Além disso, é eficaz apenas para transformadores que apresentam um manto de gás sobre o óleo, fato que ocorre apenas após a saturação do gás no volume total do tanque.

Vale ressaltar que a técnica baseada na detecção total de gases combustíveis (TCG) não determina a concentração de cada gás individualmente, fator que pode resultar em imprecisões no diagnóstico de falhas e manutenção do equipamento. No entanto, existem técnicas complementares que permitem a análise individual de cada gás a partir de amostras retiradas do manto de gases sobre o óleo. Essa técnica complementar mostrar-se mais sofisticada e apresenta resultados mais detalhados, mas apresenta as mesmas deficiências quanto à saturação dos gases sobre o manto.

O método denominado DCG (Dissolved Combustible Gases) determina com precisão a concentração dos gases dissolvidos no óleo, mesmo em fase inicial, antes de saturarem sobre o manto. No entanto, tal técnica é mais complexa e necessita de análises laboratoriais mais sofisticadas.

Os métodos de detecção e identificação TCG e DCG são baseados em análises químicas a partir de amostras do óleo dos transformadores. Existem diversas outras técnicas para o mesmo fim, que vão desde cromatografia à utilização de métodos heurísticos (ARANTES, 2005; SILVA et al., 2001). No entanto, a análise química total e individual dos gases presentes no óleo de transformadores em operação é ainda a técnica mais utilizada na manutenção preditiva desses equipamentos.

\subsection{Formação de gases no interior de transformadores}

Como descrito anteriormente, as causas para formação de gases no interior de transformadores devem-se exclusivamente às falhas elétricas e estresses térmicos. A operação dos transformadores em sobrecarga gera gases devido às perdas nos condutores dos 
enrolamentos, devido ao aquecimento tanto do óleo como da isolação solida dos enrolamentos. Como já mencionado em capítulos anteriores, alguns gases são formados também devido à eventuais descargas parciais no interior dos enrolamentos e óleo, o que contribui negativamente resultando na decomposição progressiva da isolação dos transformadores.

A decomposição da celulose com óleo impregnado, no enrolamento dos transformadores, produz os óxidos de carbono $\mathrm{CO}$ e $\mathrm{CO}_{2}$, os quais não são combustíveis. Devido à degradação do óleo em conjunto com a celulose, os gases $\mathrm{H}_{2}$ e $\mathrm{CH}_{4}$ são também formados em menor quantidade. A taxa na qual esses gases são formados depende exponencialmente da temperatura e diretamente do volume do material em uma dada temperatura. Devido a essa característica, um grande volume de isolador aquecido de forma moderada irá produzir a mesma quantidade de gás no caso de um menor volume em temperaturas mais altas (IEEE, 2008).

A decomposição do óleo dos transformadores ocorre de maneira mais complexa que a celulose. O óleo mineral é composto por uma grande quantidade de hidrocarbonetos, tornando a decomposição de tais moléculas um processo complexo, seja por falhas térmicas ou elétricas. A quebra dos hidrocarbonetos resulta em átomos livres de hidrogênio $\left(\mathrm{H}_{2}\right)$ e fragmentos de moléculas maiores de hidrocarbonetos, que por sua vez, se recombinam e formam outros gases, tais como: metano $\left(\mathrm{CH}_{4}\right)$, etano $\left(\mathrm{C}_{2} \mathrm{H}_{6}\right)$, entre outros gases combustíveis. Em uma próxima etapa, outros produtos podem ser gerados no interior dos transformadores, tais como: $\mathrm{C}_{2} \mathrm{H}_{4}$ e acetileno $\left(\mathrm{C}_{2} \mathrm{H}_{2}\right)$, ambos altamente inflamáveis. A formação desses compostos é dada em função das características do equipamento, tipo de falhas recorrentes, características de operação, entre alguns outros aspectos. De fato, é difícil predizer quais e a quantidade desses gases que será gerada. No entanto, modelos termodinâmicos permitem o cálculo da pressão parcial de cada gás em função da temperatura, representando uma ferramenta importante na análise da formação de gases no interior de transformadores. A relação de Halstead da pressão parcial em função da temperatura é uma ferramenta amplamente utilizada na análise da dinâmica de formação dos principais gases no interior de transformadores de potência, tal como descrita na figura 1 (HALSTEAD, 1973; CRUZ et al., 2015).

Observa-se na figura 1 que a quantidade formada de $\mathrm{H}_{2}$ é relativamente alta e constante em função da temperatura, enquanto que a formação de $\mathrm{C}_{2} \mathrm{H}_{2}$ torna-se significativa aproximadamente acima de $1000^{\circ} \mathrm{C}$. Desta forma, pode-se concluir de maneira antecipada, que a formação de $\mathrm{C}_{2} \mathrm{H}_{2}$ ocorre a partir de falhas envolvendo grande quantidade de energia, 
resultando em altíssimas temperaturas no óleo mineral. Falhas envolvendo grande dissipação de energia e gerando temperaturas acima de $700^{\circ} \mathrm{C}$ são quase que exclusivamente de origem elétrica, como será discutido em detalhes mais adiante. Além disso, a figura 1 mostra que a formação de $\mathrm{CH}_{4}, \mathrm{C}_{2} \mathrm{H}_{4}$ e $\mathrm{C}_{2} \mathrm{H}_{6}$ é altamente dependente da temperatura.

Figura 1 - Pressões parciais de equilíbrio térmico de Halstead em função da temperatura.

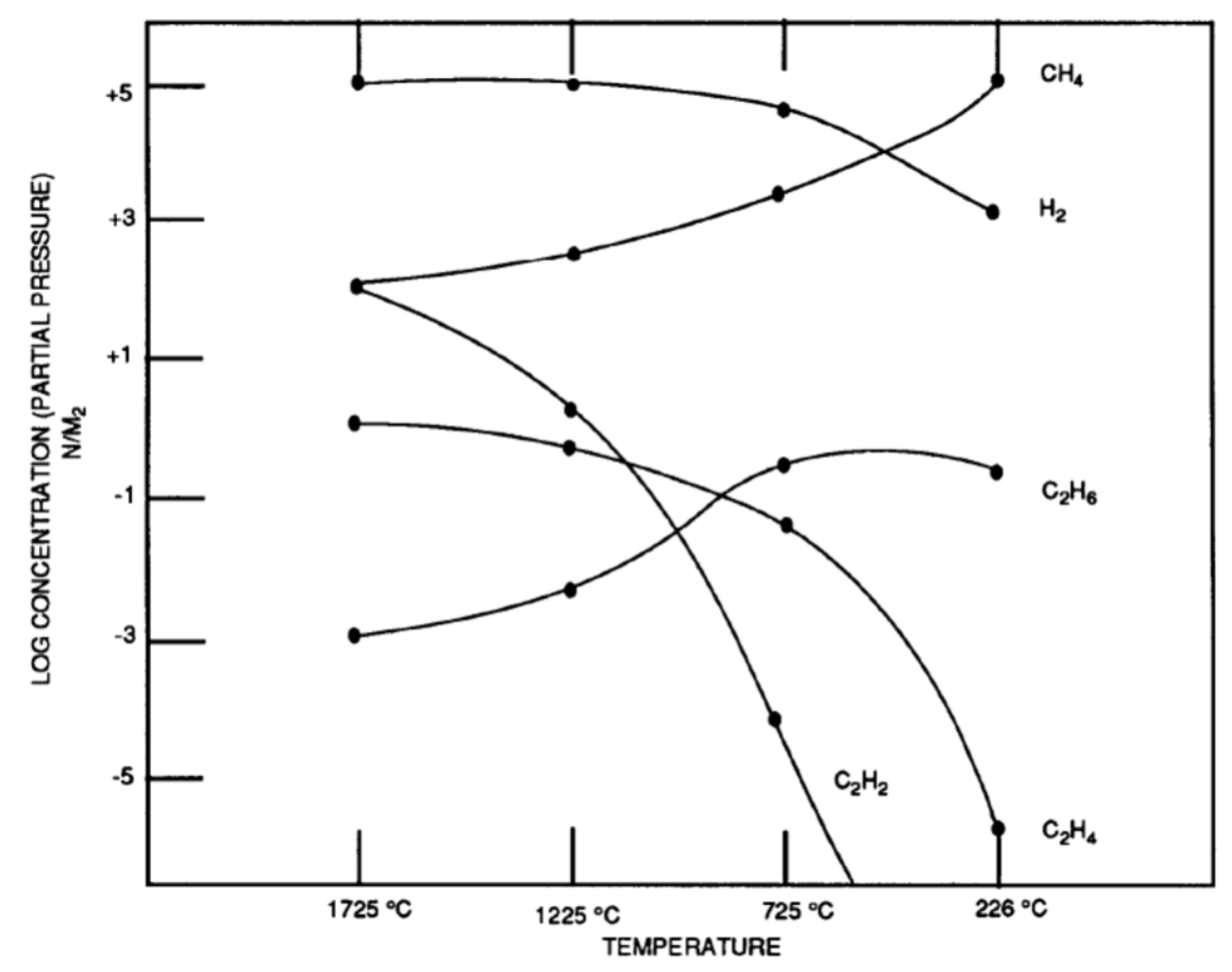

Fonte: IEEE, 2008.

Apesar da relação estabelecida por Halstead representar uma aproximação termodinâmica em condições muito particulares (óleo mineral no interior de transformadores de potência), a associação de tais dados com a concentração de cada gás no óleo dos transformadores, que pode ser obtida por meio de diversas técnicas de medição, auxilia na estimação do histórico térmico desses equipamentos em função da operação e eventuais falhas ocorridas. Por exemplo, a presença de $\mathrm{C}_{2} \mathrm{H}_{2}$ indica que o óleo do transformador atingiu altas temperaturas durante uma falta, provavelmente um arco elétrico através do óleo isolante. Por outro lado, a presença de gás $\mathrm{CH}_{4}$ indica a ocorrência de falhas caracterizadas por baixa energia elétrica e/ou térmica (IEEE, 2008). Dessa forma, pode-se verificar que por meio dos gases presentes no óleo dos transformadores é possível estimar o perfil da operação na qual 
esses dispositivos foram submetidos e falhas ocorridas, i.e., o levantamento histórico do equipamento pode ser obtido por meio da análise dos gases presentes no óleo mineral.

\subsection{Análise e interpretação dos gases}

A manutenção de grandes transformadores pode ser realizada por meio de medições e monitoramento periódico da concentração dos hidrocarbonetos, descritos na figura 1 , no óleo mineral. Convencionalmente, determina-se um ponto de concentração inicial para cada gás em transformadores novos e, com base nesse ponto de referência, realiza-se o monitoramento desses equipamentos em função de medições periódicas. Geralmente, o monitoramento pode ser realizado por meio de amostragens diárias ou semanais, seguindo-se por um espaçamento progressivo em meses e intervalos maiores. O monitoramento e intervalo de coleta das amostragens do óleo podem variar dependendo da aplicação e do equipamento a ser avaliado. Por exemplo, o intervalo de monitoramento de transformadores do tipo GSU varia de quatro a seis vezes por ano, transformadores de $765 \mathrm{kV}$ são monitorados mensalmente enquanto que unidades de até $138 \mathrm{kV}$ são monitorados duas vezes ao ano (IEEE, 2008).

A análise deve ser realizada com alguns cuidados e critérios, como por exemplo o prévio conhecimento do histórico de operação do transformador, idade, ocorrência de desligamentos, histórico de chaveamentos entre outros. A relevância deste assunto vem do fato de que, por exemplo, radiadores zincados, peças de aço inox, verniz e demais materiais produzem quantidades expressivas de $\mathrm{H}_{2}$ e $\mathrm{CH}_{4}$ até que haja o equilíbrio das reações químicas destes com o óleo.

Segundo as principais referências técnicas (IEC 60599, 2009; IEEE, 2008), a decomposição do óleo mineral a partir de $150^{\circ} \mathrm{C}$ a $500^{\circ} \mathrm{C}$ produz grande quantidade de moléculas leves, tal como $\mathrm{H}_{2}$ e $\mathrm{CH}_{2}$ e concentrações relativamente menores de gases compostos por moléculas mais pesadas, como $\mathrm{C}_{2} \mathrm{H}_{4}$ e $\mathrm{C}_{2} \mathrm{H}_{6}$. Essa faixa de temperatura enquadra-se na categoria das falhas denominadas térmicas, geralmente decorrentes de falhas de produção ou projeto (e.g. pontos quentes) ou sobrecarga na operação de transformadores de potência. Em temperaturas próximas à $500^{\circ} \mathrm{C}$, maiores concentrações de $\mathrm{H}_{2}$ e $\mathrm{C}_{2} \mathrm{H}_{4}$ são produzidas em conjunto com menores concentrações de $\mathrm{C}_{2} \mathrm{H}_{4}$. Diferentemente da degradação do óleo mineral por falhas térmicas, a decomposição da celulose, que compõe a isolação sólida dos transformadores, produz monóxido de carbono $\mathrm{CO}$, dióxido de carbono $\mathrm{CO}_{2} \mathrm{e}$ vapor de água em temperaturas abaixo das quais o óleo mineral é degradado. Dessa forma, é comum encontrar traços de $\mathrm{CO}$ e $\mathrm{CO}_{2}$ junto aos hidrocarbonetos gerados a partir da 
degradação do óleo mineral (ASTM, 2002). Ressaltando-se que apenas os gases formados a partir do óleo mineral são combustíveis e altamente inflamáveis.

No caso da degradação térmica da celulose, devido aos eventuais pontos quentes no interior dos transformadores, a relação $\mathrm{CO}_{2} / \mathrm{CO}$ mostra-se um indicador relativamente confiável. Essa relação torna-se ainda mais confiável para níveis acima de 5000 partes por milhão (ppm) de $\mathrm{CO}_{2}$ e acima de 500 ppm de $\mathrm{CO}$. Desse modo, casos em que $\mathrm{CO}_{2} / \mathrm{CO}>5$ indicam degradação anormal da celulose devido ao efeito térmico em função de eventuais pontos quentes ou sobrecarga na operação do transformador (IEEE, 2008; ASTM, 2002).

No caso da degradação do óleo mineral devido às falhas elétricas de baixa intensidade (e.g. descarga parciais), observa-se maior concentração de $\mathrm{H}_{2}$ e pequenas concentrações de $\mathrm{CH}_{4}$ e $\mathrm{C}_{2} \mathrm{H}_{2}$. Por outro lado, considerando-se falhas elétricas de alta intensidade (e.g. arcos elétricos), com temperaturas entre $700^{\circ} \mathrm{C}$ a $1800^{\circ} \mathrm{C}$, a quantidade produzida de $\mathrm{C}_{2} \mathrm{H}_{2}$ é acentuadamente maior que dos demais gases, tal como observado na relação dos gases descrita na figura 1. Dessa forma, sabendo-se a proporção aproximada da formação de gases, combustíveis ou não, é possível determinar o tipo de falta ocorrido. A figura 2 descreve a proporção dos gases formados para os principais tipos de falta em transformadores.

Figura 2 - Identificação de falhas em função da proporção relativa de gases.
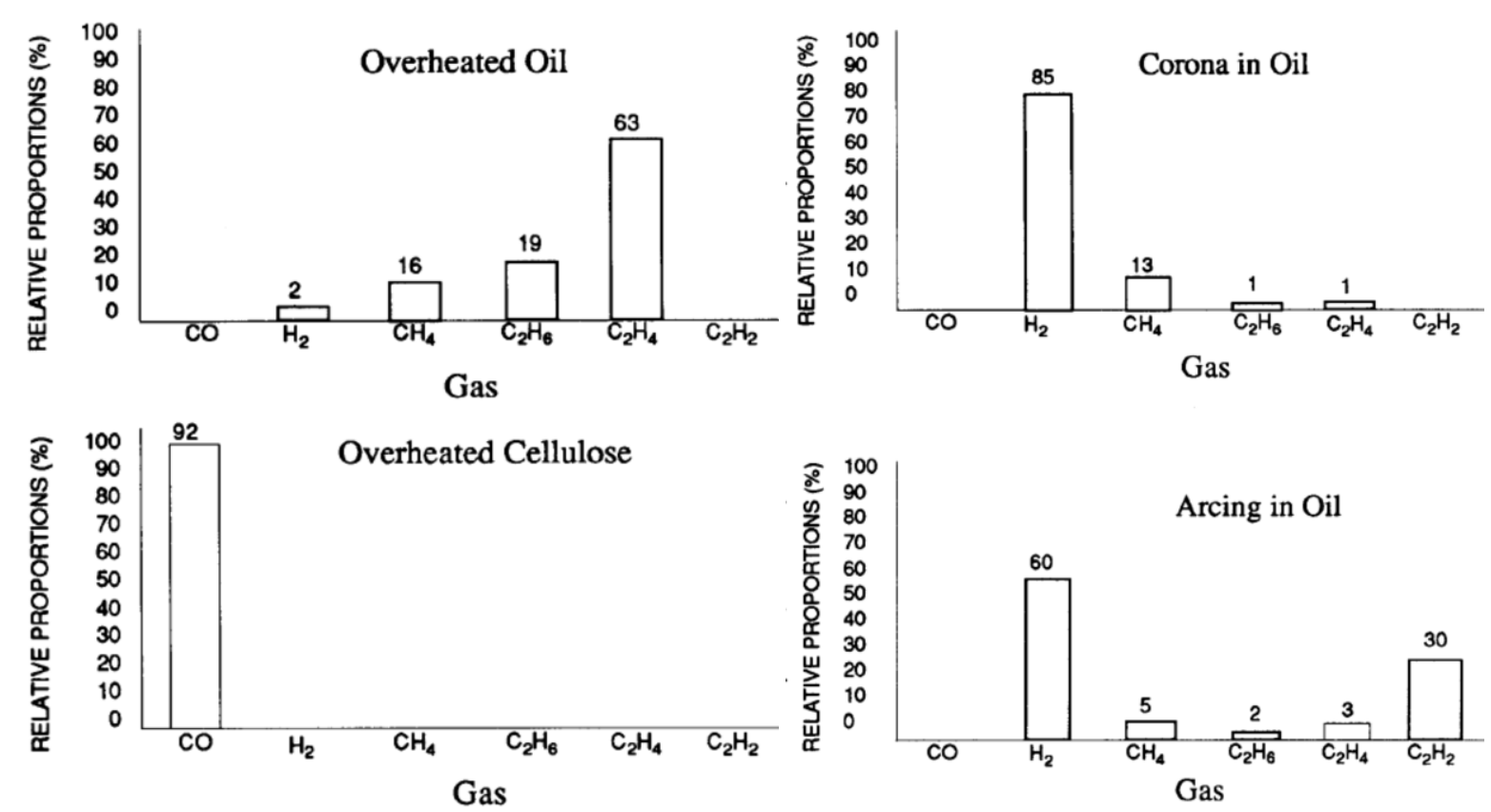

Fonte: IEEE, 2008. 
A figura 2 descreve a proporção relativa de gases para quatro tipos de falhas distintas em transformadores. Cada gráfico descreve uma espécie de "assinatura" para cada tipo de falta, seja térmica ou elétrica.

Falhas devido ao sobreaquecimento do óleo mineral (Overheated Oil) resultam em maiores concentrações de $\mathrm{C}_{2} \mathrm{H}_{4}$ e $\mathrm{CH}_{4}$ associadas a menores concentrações de $\mathrm{H}_{2}$ e $\mathrm{C}_{2} \mathrm{H}_{6}$. No entanto, dependendo da severidade da falta, $\mathrm{C}_{2} \mathrm{H}_{2}$ pode ser encontrado em menores concentrações. O principal gás formado em falhas térmicas por sobreaquecimento do óleo é o $\mathrm{C}_{2} \mathrm{H}_{4}$. Por outro lado, falhas térmicas envolvendo isolantes sólidos, mais especificamente celulose (Overheated Cellulose), são responsáveis pela formação de monóxido de carbono, sem a presença de hidrocarbonetos.

A partir da figura 2, observa-se também que falhas elétricas devido ao efeito corona (Corona in Oil), que representam descargas com baixa energia elétrica, produzem maiores concentrações de $\mathrm{H}_{2}$ e $\mathrm{CH}_{4}$, com pequenas concentrações de $\mathrm{C}_{2} \mathrm{H}_{6}$ e $\mathrm{C}_{2} \mathrm{H}_{4}$. Traços de monóxido e dióxido de carbono podem ser encontrados se as descargas se formarem através da celulose. No entanto, o $\mathrm{H}_{2}$ representa aproximadamente $85 \%$ dos gases formados no interior dos transformadores nesse tipo de falta.

No caso das falhas caracterizadas pela dissipação de grande quantidade de energia elétrica, por meio da formação de arcos elétricos no interior dos transformadores (Arcing in Oil), é gerada uma grande concentração de $\mathrm{H}_{2}$ e $\mathrm{C}_{2} \mathrm{H}_{2}$, com menores quantidades de $\mathrm{CH}_{4}$ e $\mathrm{C}_{2} \mathrm{H}_{4}$. Óxidos de carbono podem ser gerados se o arco ocorrer através da isolação de celulose. No entanto, o principal gás formado a partir de arcos elétricos no interior de transformadores é o $\mathrm{C}_{2} \mathrm{H}_{2}$, como descrito na figura 2 .

Portanto, verifica-se que para cada tipo de falta existe um denominado gás chave, do termo na língua inglesa Key Gas, que é predominante em relação à concentração dos outros gases. A formação de cada gás é dada em função da temperatura do óleo, como descrito anteriormente, e pode ser exemplificada por meio da figura 3. 
Figura 3 - Concentração dos gases em função da temperatura.

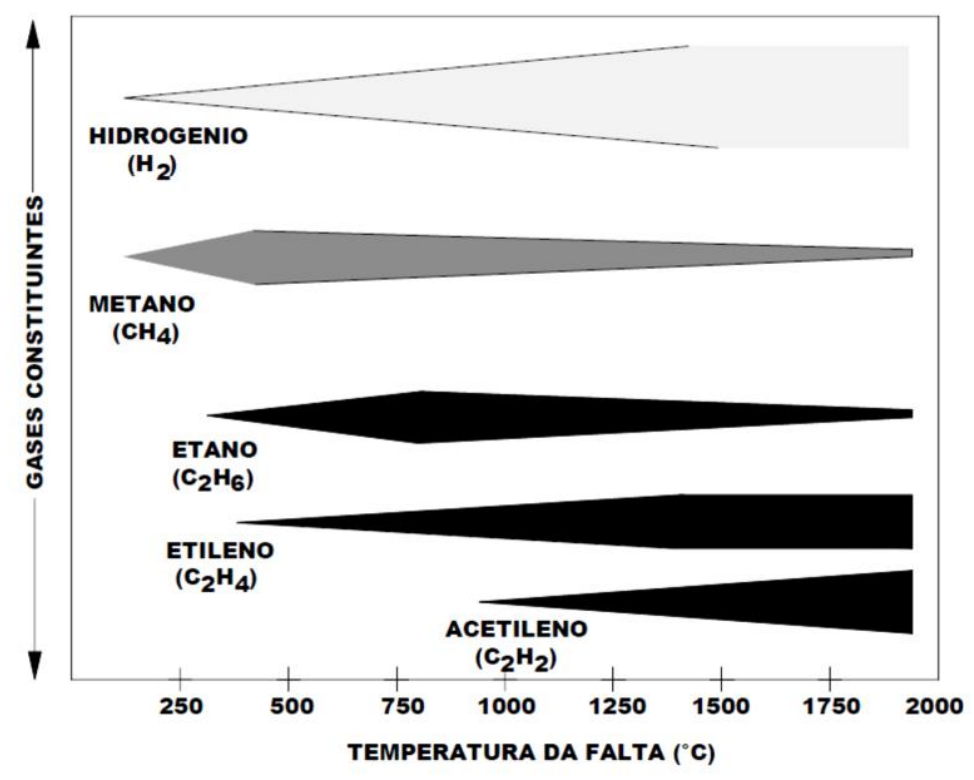

Fonte: ARANTES, 2005

A partir da figura 3, observa-se que a formação de $\mathrm{C}_{2} \mathrm{H}_{2}$ se dá a partir de temperaturas acima de $900^{\circ} \mathrm{C}$, típicas de falhas envolvendo arcos elétricos no interior dos transformadores. Por outro lado, $\mathrm{H}_{2}$ e $\mathrm{CH}_{4}$ são gerados a partir de temperaturas acima de 100-120 ${ }^{\circ} \mathrm{C}$, típicas de falhas térmicas envolvendo pontos quentes em transformadores ou operação continua em sobrecarga.

Portanto, observa-se que o tipo de falta nos transformadores pode ser identificado pelo denominado Método do Gás Chave. Trata-se basicamente da verificação da concentração individual de cada gás presente no óleo do transformador e, a partir das descrições apresentadas nas figuras 1 e 2, determinar o tipo de falta com base nos principais gases gerados. A tabela 1 descreve em detalhes o método em questão (IEEE, 2008). 
Tabela 1 - Diagnóstico pelo Método do Gás Chave.

\begin{tabular}{|c|c|c|c|}
\hline FALTA & GÁS CHAVE & CARACTERISTICAS & \% GÁS \\
\hline Arco Elétrico & $\begin{array}{l}\text { Acetileno } \\
\left(\mathrm{C}_{2} \mathrm{H}_{2}\right)\end{array}$ & $\begin{array}{l}\text { Maiores concentrações de } \\
\text { hidrogênio e acetileno. Eventual } \\
\text { presença de monóxido e dióxido } \\
\text { de carbono indica que a celulose } \\
\text { dos enrolamentos foi afetada. }\end{array}$ & $\begin{array}{l}\mathrm{H}_{2}: 60 \% \\
\mathrm{C}_{2} \mathrm{H}_{2}: 30 \%\end{array}$ \\
\hline Corona & $\begin{array}{l}\text { Hidrogênio } \\
\qquad\left(\mathrm{H}_{2}\right)\end{array}$ & $\begin{array}{l}\text { Maiores concentrações de } \\
\text { hidrogênio e um pouco de } \\
\text { metano. Eventual presença de } \\
\text { monóxido e dióxido de carbono } \\
\text { indica que a celulose dos } \\
\text { enrolamentos foi afetada. }\end{array}$ & $\begin{array}{l}\mathrm{H}_{2}: 85 \% \\
\mathrm{CH}_{4}: 13 \%\end{array}$ \\
\hline $\begin{array}{l}\text { Sobreaquecimento } \\
\text { do óleo }\end{array}$ & $\begin{array}{l}\text { Etileno } \\
\left(\mathrm{C}_{2} \mathrm{H}_{4}\right)\end{array}$ & $\begin{array}{l}\text { Maiores concentrações de } \\
\text { etileno e menor concentração de } \\
\text { etano. Podem existir pequenas } \\
\text { concentrações de hidrogênio e } \\
\text { óxidos de carbono. }\end{array}$ & $\begin{array}{l}\mathrm{C}_{2} \mathrm{H}_{4}: 63 \% \\
\mathrm{C}_{2} \mathrm{H}_{6}: 20 \%\end{array}$ \\
\hline $\begin{array}{c}\text { Sobreaquecimento } \\
\text { da celulose }\end{array}$ & $\begin{array}{l}\text { Monóxido de } \\
\text { Carbono } \\
\text { (CO) }\end{array}$ & $\begin{array}{l}\text { Grande concentração de } \\
\text { monóxido de carbono com } \\
\text { menor concentração de dióxido } \\
\text { de carbono. Hidrocarbonetos } \\
\text { podem existir se o óleo foi } \\
\text { sobreaquecido. }\end{array}$ & CO: $92 \%$ \\
\hline
\end{tabular}

Fonte: IEEE, 2008. 


\section{Transformadores de potência}

De acordo com a definição apresentada na literatura técnica, um transformador consiste em duas ou mais bobinas acopladas por fluxo magnético mútuo ou compartilhado. Se um dos enrolamentos, o primário, estiver conectado a uma fonte de tensão alternada, um fluxo magnético será produzido cuja amplitude depende da tensão do primário, tanto quanto a frequência do sinal de tensão aplicado e do número de espiras do enrolamento. O fluxo mútuo irá interligar o enrolamento primário ao secundário e irá induzir uma tensão cuja magnitude irá depender do número de bobinas do enrolamento secundário e do módulo e frequência do fluxo magnético gerado pelo primário. A relação de transformação da tensão é definida pela proporção da quantidade de bobinas do enrolamento primário em relação ao secundário, convencionalmente interligados apenas por um núcleo de material ferromagnético com alta permeabilidade magnética, composto por finas laminas de aço silício (Fitzgerald, 2003).

A literatura técnica descreve o princípio de funcionamento dos transformadores, sendo o mesmo nos últimos 150 anos. No entanto, a parte ativa dos transformadores, representada pelos enrolamentos e núcleo ferromagnético, representa apenas uma parte no projeto dos atuais transformadores de potência, que inclui também técnicas de isolação elétrica modernas, refrigeração da isolação liquida (óleo mineral), detecção de gases, ensaios de aceitação e técnicas de monitoramento e proteção.

Neste capitulo são introduzidas algumas das principais características construtivas de transformadores do tipo GSU, utilizados na elevação da tensão a partir das unidades geradoras à rede de transmissão, geralmente em níveis de tensão acima de $230 \mathrm{kV}$. A figura 4 mostra um transformador GSU e seus principais componentes: bucha de alta tensão (1), bucha de baixa tensão (2), para-raios de óxido metálico (3), radiador com ventiladores (4), conservador de óleo (5) e o tanque onde os enrolamentos e o núcleo ferromagnético encontram-se imersos em óleo mineral (6).

Vale destacar que existem diversos outros componentes que não estão explícitos na figura 4 e que também serão discutidos ao longo deste capitulo, tais como: canecos das buchas; detalhes sobre o conservador; termômetros; sistema de ventilação forçada; válvulas de alívio de pressão; relés de gás e de pressão súbita; canecos das buchas; mecanismos dos comutadores com carga (On Load Tap Changer - OLTC) e sem carga (De-Energized Tap Changer - DETC); dentre diversos outros componentes essenciais para funcionamento e monitoramento adequado de grandes transformadores de potência. 
Figura 4 - Transformador do tipo GSU.

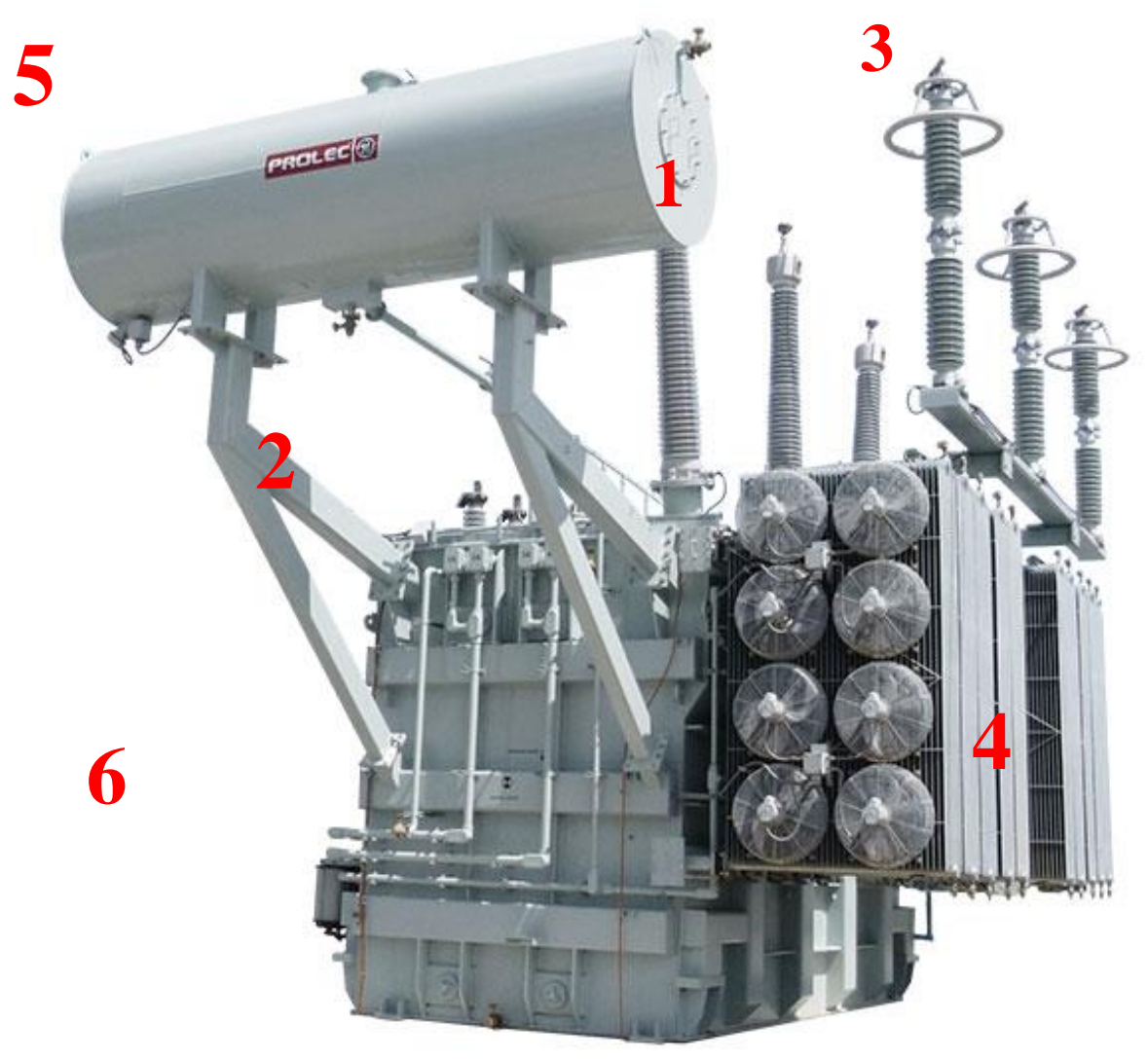

Fonte: General Electric Company

Ainda na figura 4, é interessante destacar os para-raios de $\mathrm{ZnO}$ instalados diretamente no corpo do transformador, junto às buchas de alta tensão. Convencionalmente, esses dispositivos de proteção são instalados próximos à saída do transformador GSU em pedestais independentes, com o objetivo de suprimir eventuais sobretensões resultantes de impulsos atmosféricos ou de manobras no sistema.

A figura 5 a mostra a parte superior do transformador GSU de $120 \mathrm{MVA}, 13,8 / 230 \mathrm{kV}$, considerado nas análises realizadas nesse trabalho. Na figura $5 a$ são descritos o conservador de óleo, buchas de alta e baixa tensão, radiadores e ventiladores. A figura $5 b$ mostra em maiores detalhes a parte superior do mesmo transformador, destacando os tubos de fluxo de óleo, tampas de inspeção na parte superior do tanque, válvula de alivio da pressão e canecos das buchas de alta e baixa tensão. 
Figura 5 - Transformador GSU de 120 MVA - 13,8/230 kV.

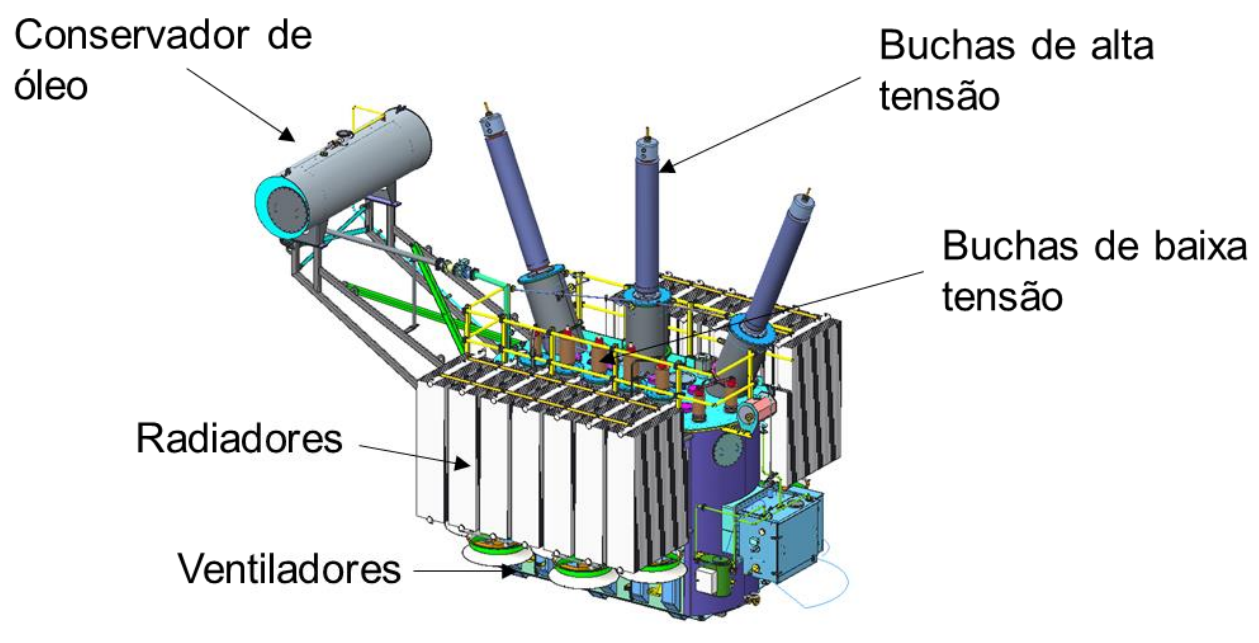

(a)

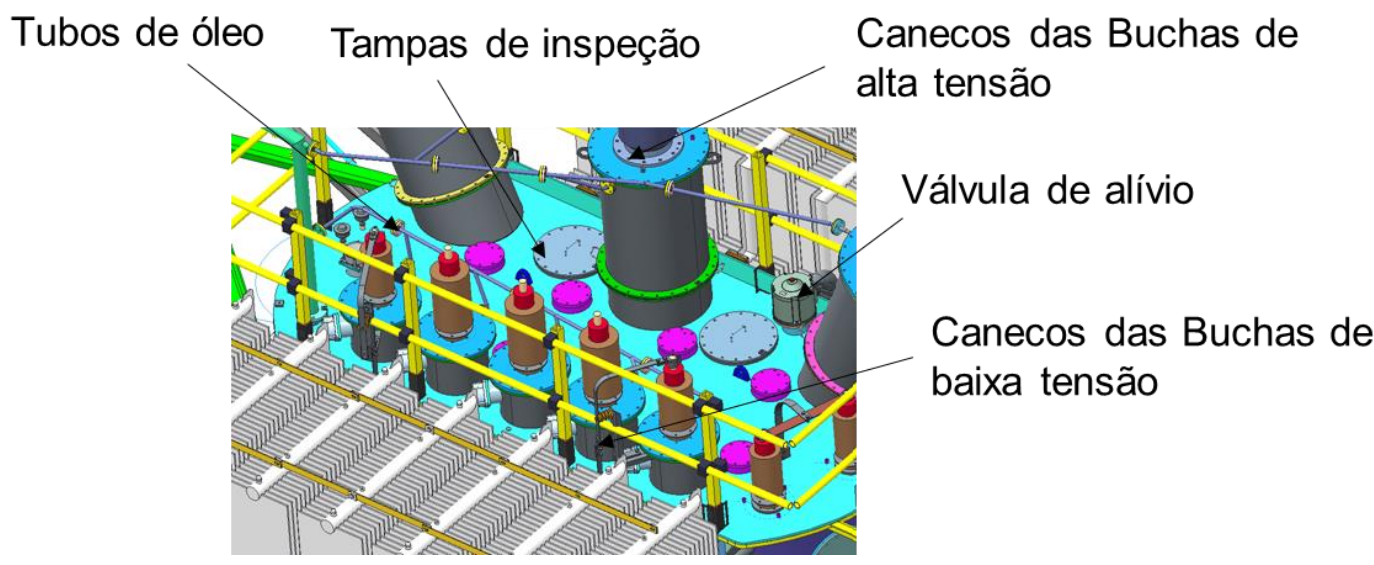

(b)

Fonte: Próprio Autor

Alguns dos componentes descritos até o momento podem ou não estar presentes no projeto de transformadores de potência, dependendo da aplicação do equipamento, fabricante e especificações do cliente. No entanto, a maior parte desses componentes é especifica de transformadores do tipo GSU e serão discutidas com algum detalhamento ao longo deste capítulo.

\subsection{Bucha de porcelana e canecos de fixação}

As buchas de porcelana, de alta e baixa tensão, são fixadas sobre os canecos metálicos cilíndricos, que por sua vez, abrigam os transformadores de corrente (TC) para fins de monitoramento, medição e imagem térmica. Dentro destes canecos, os TCs estão montados na 
terminação das buchas (pé de bucha), apoiados em suportes metálicos. As buchas são fixadas através de flanges parafusadas e com sistema de vedação do óleo através de gaxetas especiais, compatíveis com o óleo isolante e à temperatura que as peças mecânicas irão alcançar em operação.

As buchas são dispositivos estanques, caracterizados por estreitos tanques de expansão para permitir a dilatação do pequeno volume interno de óleo sem que ocorra a infiltração de umidade, ar e outros agentes externos. No interior do corpo de porcelana há um condutor sólido de cobre, ou um tubo de alumínio, envolvido em celulose impregnada de óleo isolante. $\mathrm{O}$ volume de óleo no interior das buchas é relativamente pequeno se comparado com o volume existente no interior do tanque do transformador, dessa forma, o monitoramento das condições de conservação da isolação no interior das buchas torna-se uma tarefa complexa.

Existem basicamente dois tipos de bucha para transformadores. A primeira consiste simplesmente de um condutor envolto pelo invólucro de porcelana, utilizadas em aplicações com nível de tensão inferiores a $15 \mathrm{kV}$, são denominadas buchas com corpo não condensivo. O segundo tipo, com corpo condensivo, é caracterizada por diversas camadas de filme metálico envolto por celulose impregnada e imerso em óleo isolante, entre o condutor sólido e a parte interna do corpo de porcelana. O corpo condensivo tem como objetivo equalizar o campo elétrico distribuído ao longo da bucha, principalmente em transformadores do tipo GSU com níveis de tensão acima de $230 \mathrm{kV}$ para prover a passagem dos condutores através da tampa metálica do transformador, realizando a interface óleo-ar, óleo-SF6, dependendo do tipo de subestação utilizada.

As buchas são fixadas na parte superior dos canecos metálicos, que por sua vez, abrigam no seu interior vários TCs para fins de medição de corrente elétrica, como descrito em detalhes na figura 6. 
Figura 6 - Bucha de baixa tensão fixada sobre o caneco e transformador de corrente.

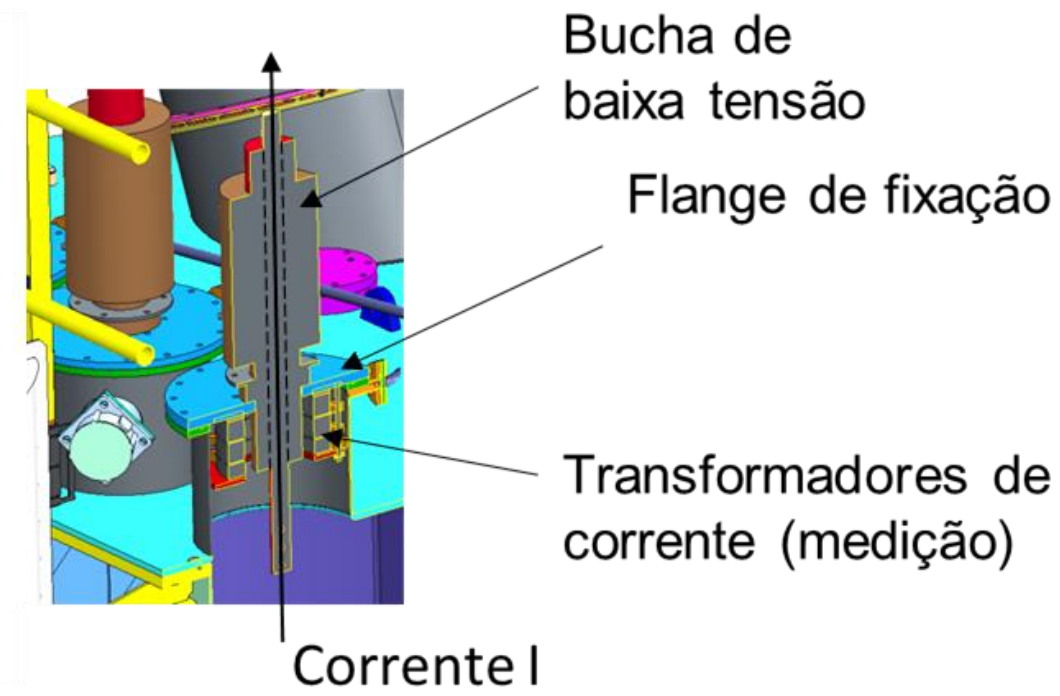

Fonte: Próprio Autor

\subsection{Conservador de óleo}

O conservador de óleo, também conhecido como tanque de expansão, descrito nas figuras 4 e 5, trata-se de um reservatório auxiliar conectado diretamente ao tanque do transformador de modo a mantê-lo sempre cheio. O conservador encontra-se parcialmente cheio de óleo, havendo espaço para eventual expansão e contração do óleo no interior do tanque do transformador, devido às variações na temperatura e pressão. O conservador de óleo é descrito em detalhes na figura 7. 
Figura 7 - Conservador de óleo (tanque de expansão).

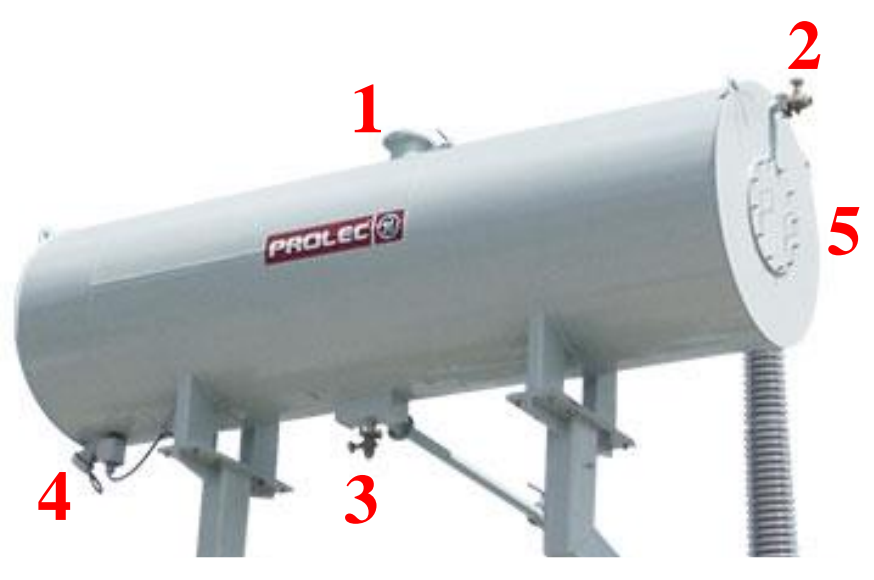

Fonte: General Electric Company

Algumas das principais partes do conservador de óleo são destacadas na figura 8: válvula equalizadora (1), responsável pelo fluxo de ar entre o conservador de óleo e o meio ambiente; válvula de enchimento (2); válvula de drenagem (3); indicador do nível do óleo (4); tampa removível (5).

O conservador de óleo pode ainda ser equipado com uma bolsa de borracha (figura 8) intermediaria entre o meio ambiente e o óleo isolante. A bolsa de borracha trata-se de um acessório adicional conectado à válvula equalizadora, responsável pelo fluxo de ar durante a expansão e contração do óleo no interior do tanque do transformador e do conservador. Essa bolsa de borracha evita o contato do ar externo com o óleo no interior do conservador, preservando-o da umidade e eventual oxidação. A ligação da bolsa com o meio ambiente é realizada por meio de um secador de ar a base de sílica, mantendo o ar seco no interior da bolsa, permitindo que se encha ou esvazie em função apenas das variações de volume do óleo isolante. 
Figura 8 - Bolsa de borracha utilizada no interior do conservador de óleo.

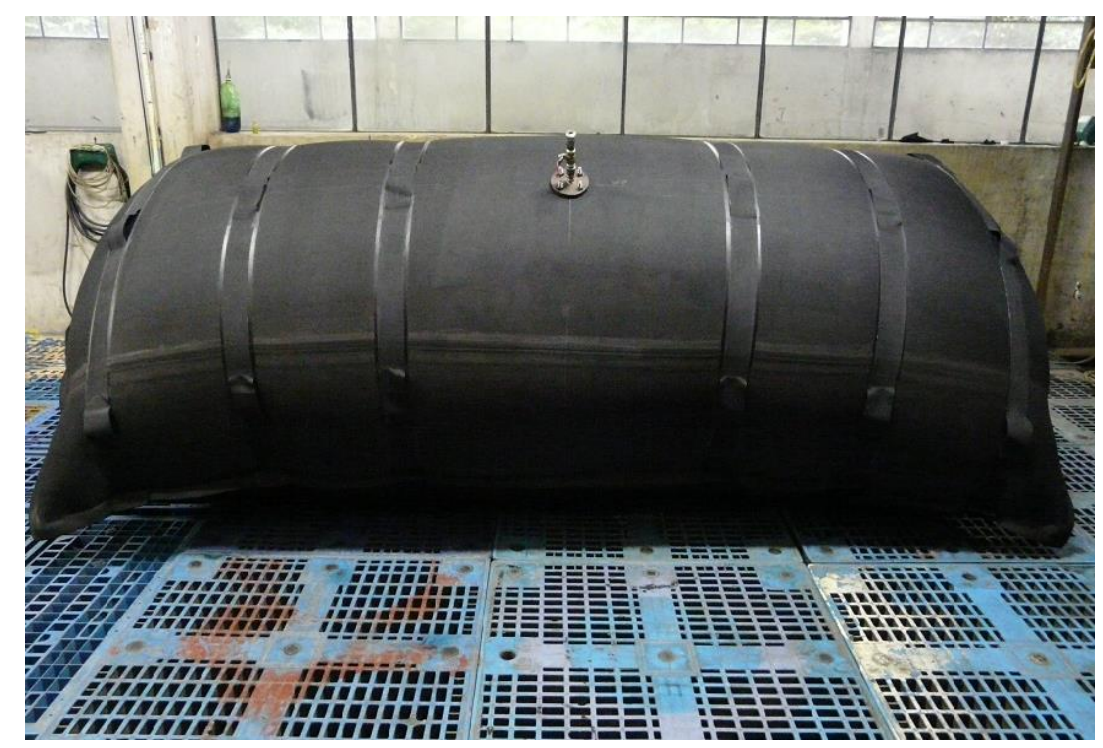

Fonte: Flecha Artefatos de Borracha Ltda.

Vale ressaltar que o ar contido no interior da bolsa de borracha não tem contato com o óleo isolante no interior do conservador. O fluxo de ar entre a bolsa e o meio ambiente se dá exclusivamente em função da expansão e contração do óleo no interior do transformador, por meio da válvula equalizadora e da válvula observada na parte superior da bolsa de borracha da figura 8. Existem sensores específicos, que são ou não especificados pelo usuário, pra detecção da ruptura desta bolsa.

\subsection{Medição do nível e da temperatura do óleo}

Os medidores magnéticos de nível do óleo, tal como a própria denominação descreve, têm como objetivo indicar o nível do óleo do conservador e do tanque do transformador. Alguns desses dispositivos são providos de sistema de alarme e proteção, caso o nível do óleo esteja fora da faixa de operação adequada do transformador.

Na figura 7, o indicador magnético de nível encontra-se instalado no conservador de óleo. No entanto, dependendo do projeto do transformador, o indicador de nível pode ser instalado diretamente no tanque principal. Geralmente, esse dispositivo possui carcaça de alumínio fundido e a indicação de nível do óleo é realizada por meio de um ponteiro conectado a um imã permanente. O visor do indicador magnético apresenta os pontos de 
mínimo e máximo nível do óleo, como descrito no esquema na figura 9, obtido a partir do catálogo de um fabricante nacional de transformadores de até 100 MVA.

Figura 9 - Indicador de nível de óleo.
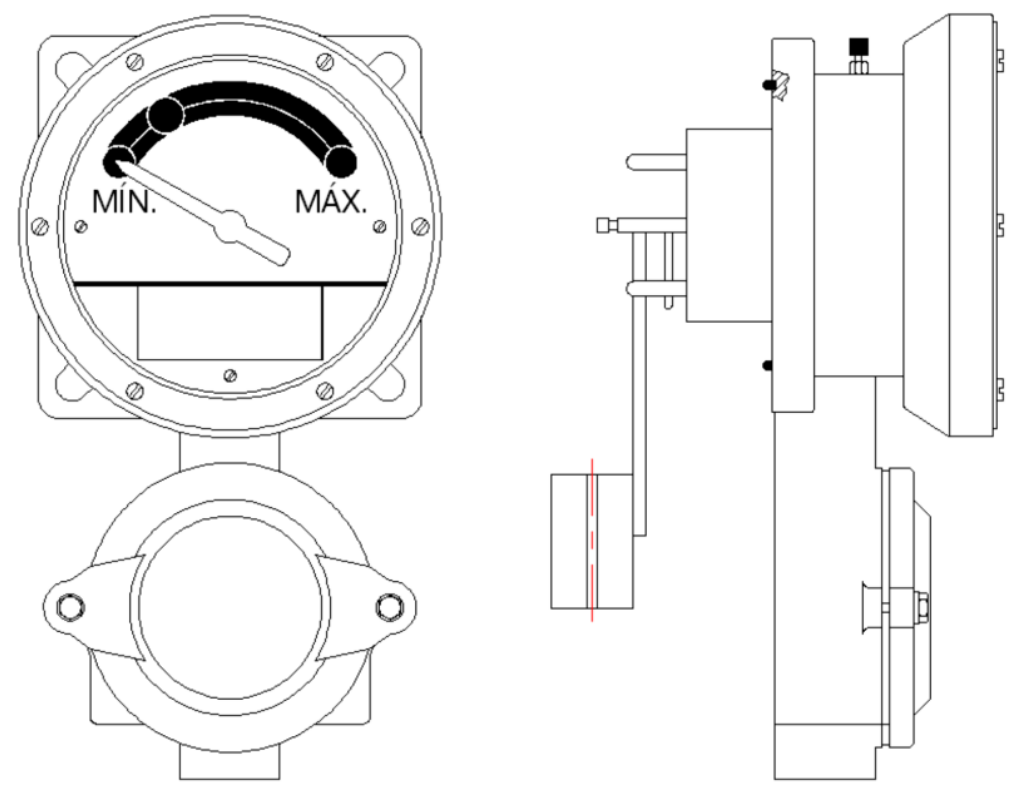

Fonte: COMTRAFO S.A.

A medição da temperatura do óleo pode ser realizada fazendo uso dos indicadores de nível. Geralmente, o visor do indicador magnético marca a temperatura ambiente de $25^{\circ} \mathrm{C}$ para um dado nível do óleo, dessa forma, pode-se obter a temperatura aproximada em função da expansão e contração do óleo, que estão diretamente relacionadas com o nível do óleo no tanque principal e de expansão. No entanto, os transformadores de grande porte estão equipados com dispositivos de medição mais precisos para monitoramento da temperatura do óleo no interior dos tanques.

Os termômetros de óleo mais modernos são capazes de medir a temperatura instantânea, temperatura máxima e mínima durante certo período de operação do transformador. Esses dispositivos são capazes de acionar a ventilação forçada, soar alarmes de sobreaquecimento e desligar o equipamento em temperaturas predefinidas pelo operador. Por exemplo, a ventilação forçada é acionada em $70^{\circ} \mathrm{C}$, alarme de sobreaquecimento à $90^{\circ} \mathrm{C}$ e desligamento à $100^{\circ} \mathrm{C}$. Esses valores são ajustados de acordo com a operação, características e aplicação do transformador de potência a ser monitorado. 
Existe ainda a possibilidade de medir diretamente a temperatura do cobre dos enrolamentos através de sensores com fibra ótica, que são aptos a sobreviver e medir em ambientes de alta solicitação dielétrica (SOUZA, A. et al. 2016).

\subsection{Controle da pressão no interior dos transformadores}

Basicamente, existem dois dispositivos principais para o controle da pressão no interior dos transformadores: relés de pressão súbita e válvula de alívio de pressão.

O relé de pressão súbita (Sudden Pressure Relay ou Rapid Pressure Rise Ralay) é um dispositivo instalado normalmente na lateral do tanque principal dos transformadores, entre o nível máximo do óleo e a tampa superior do tanque. Como a própria denominação descreve, é um dispositivo que atua quando a pressão interna no transformador aumenta de forma abrupta, como por exemplo, a partir de uma falha interna produzida por arco elétrico, podendo atingir temperaturas de até $1800^{\circ} \mathrm{C}$ (como descrito no capítulo anterior). Esse dispositivo atua instantaneamente mediante variações na pressão interna em torno de 0,2 atm/s, ou seja, não atuando em variações lentas de pressão durante o funcionamento normal do transformador (COMTRAFO, 2011).

Figura 10 - Relé de pressão súbita.

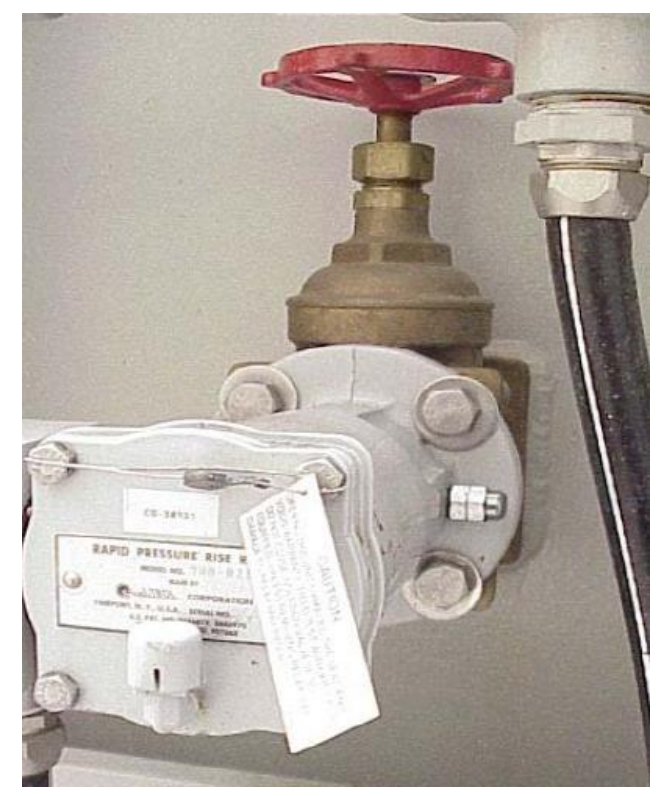

Fonte: U. S. Department of the Interior, 2003.

A válvula de alívio de pressão é instalada no tanque dos transformadores com o objetivo de evitar possíveis deformações, ou mesmo ruptura do tanque, resultantes do 
aumento da pressão interna devido a falhas ou sobrecarga na operação. Diferente do relé de pressão súbita, esse dispositivo atua independentemente do tipo de falha e velocidade na variação da pressão interna do transformador. Esse dispositivo é composto por mola que atua mediante o aumento da pressão interna no tanque, permitindo o fluxo de ar e gases do interior do tanque para o ambiente externo. Após a atuação, a válvula fecha-se automaticamente, impedindo a entrada de ar do meio ambiente para o interior do tanque.

\subsection{Relé de detecção de gases}

Como descrito no capítulo anterior, diferentes tipos de falhas no interior dos transformadores geram diferentes tipos e proporção de gases combustíveis ou não. A detecção desses gases em tempo hábil pode evitar maiores danos ao transformador e consequentemente interrupções no fornecimento de energia elétrica. Neste contexto, a utilização de relés para detecção de gases do tipo Buchholz se faz necessária (figura 11).

$\mathrm{O}$ relé de detecção de gases é normalmente instalado entre o tanque principal e o conservador de óleo (tanque de expansão) do transformador. Esse dispositivo apresenta dois visores graduados que indicam o volume de gás detectado e duas aberturas flangeadas. A produção excessiva de gás, durante uma falha de origem térmica e/ou elétrica, provoca circulação de gás através dos flanges do relé, que por sua vez, aciona um contato elétrico que emite um alarme ou/e desconecta o transformador da rede. Uma vez acionado, o gás retido no interior do relé pode ser analisado e o Método do Gás Chave, descrito no capítulo anterior, pode ser utilizado para detectar o tipo de falta e eventuais defeitos no transformador.

Figura 11 - Relés para detecção de gases do tipo Buchholz.

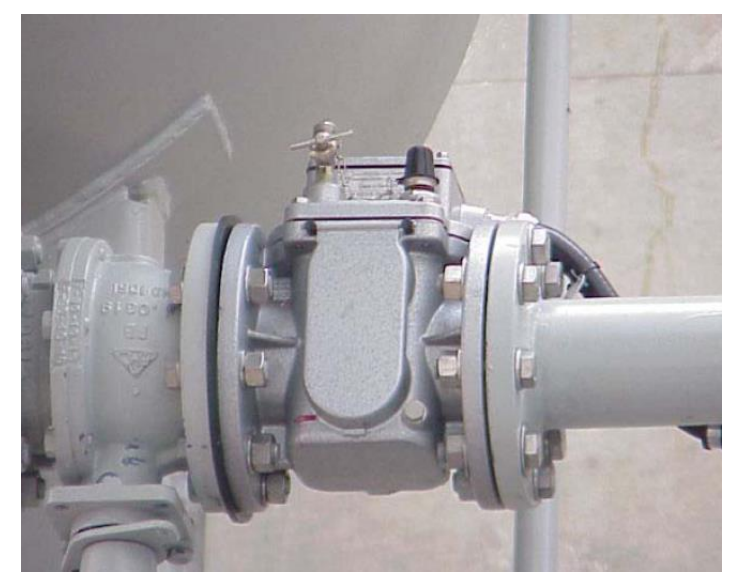

Fonte: U. S. Department of the Interior, 2003. 


\subsection{Outros componentes de transformadores de potência}

Neste capítulo foram listados alguns dos principais componentes de transformadores de potência, especialmente aqueles de grande porte. No entanto, vale destacar que existem diversos outros componentes essenciais para o funcionamento adequado dos transformadores que não foram descritos em maiores detalhes nesse item, como por exemplo: OLTC, sistema de refrigeração forçada (radiadores e ventiladores), termômetro para monitoramento da temperatura dos enrolamentos e medições diretas com fibra óptica.

O OLTC é um mecanismo que permite a variação do número de espiras dos enrolamentos de alta tensão. A finalidade desse mecanismo é corrigir o desnível de tensão existente na rede, devido à queda de tensão no sistema de distribuição ou transmissão. $\mathrm{O}$ acionamento desse mecanismo pode ser elétrico de forma remota, elétrico por comando local ou mesmo manual. A comutação pode ser realizada com o transformador com e sem carga.

O sistema de refrigeração forçada é basicamente composto pelos radiadores e ventiladores a esses acoplados. Geralmente, a refrigeração forçada é acionada quando o óleo do transformador se encontra acima de uma dada temperatura, que pode variar de acordo com o projeto do transformador e aplicação.

O termômetro para monitoramento da temperatura dos enrolamentos, também denominado na literatura técnica como termômetro de imagem térmica, é assim chamado por reproduzir de maneira indireta a temperatura do enrolamento, considerado o componente mais quente do transformador em condições normais de operação e projeto. Esse termômetro é composto por uma resistência e um sensor de temperatura simples, ambos encapsulados e inseridos em um orifício protetor imerso em óleo. Esse componente é instalado na tampa do transformador, permanecendo na mesma temperatura do óleo no topo do tanque, indicando assim a temperatura do ponto mais quente do enrolamento. Essa espécie de sonda, composta pela resistência e sensor de temperatura, trabalha em conjunto com um TC associado ao enrolamento secundário que se deseja medir do transformador principal, segundo o manual de instruções de um fabricante nacional de transformadores (COMTRAFO, 2011). 


\section{Cálculo e medição da temperatura nos pontos quentes}

\subsection{Introdução}

O transformador de potência utilizado para o fim proposto neste trabalho trata-se de um transformador do tipo GSU de 120 MVA, projetado para interligar uma fazenda eólica ao sistema de transmissão em $230 \mathrm{kV}$. Os pontos quentes no transformador são analisados fazendo-se uso do MEF (descrito em maiores detalhes em futuras seções) e utilizando-se uma formulação analítica, desenvolvida neste capítulo a partir da Lei de Biot-Savart. Ambos os métodos são validados por meio de medições termográficas, a partir da medição da radiação infravermelha emitida pelo transformador.

O objetivo deste capítulo é descrever o método analítico para o cálculo da temperatura nos pontos quentes do transformador, em função do campo magnético de dispersão sobre as partes ferromagnéticas externas ao núcleo do transformador. A priori, no projeto de grandes transformadores de potência, não deveriam existir peças ferromagnéticas além do núcleo, pois o fluxo de dispersão do próprio enrolamento resulta em correntes parasitas nessas peças, o que por sua vez, resulta em sobreaquecimento do equipamento e do óleo isolante. Contudo, mecânica e economicamente, faz-se necessária a aplicação de materiais ferromagnéticos nas partes estruturais. A existência de componentes ferromagnéticos externos ao núcleo do transformador e sujeitas a altos fluxos magnéticos pode ser caracterizada como uma falha de projeto se não estiverem previstos na concepção da máquina, pois podem gerar temperaturas acima de $120^{\circ} \mathrm{C}$ quando imersas no óleo isolante, resultando na formação de gases combustíveis no interior do equipamento. A literatura técnica descreve que temperaturas entre $135^{\circ} \mathrm{C}$ a $140^{\circ} \mathrm{C}$ são aceitáveis apenas em pequenas áreas no equipamento. Por outro lado, quando tais temperaturas se estendem por grandes superfícies, existe grande probabilidade de formação de gases hidrocarbonetos combustíveis (KARSAI et al., 1987).

Desta forma, neste capítulo são descritos os fundamentos do método analítico utilizado para o cálculo da temperatura dos pontos quentes do transformador, comparando-se os resultados obtidos com as temperaturas calculadas a partir do MEF e aos valores medidos por meio de análise termográfica. São também analisados os gases formados em função das altas temperaturas geradas pelos pontos quentes, resultantes da utilização equivocada dos materiais estruturais no transformador de potência em análise. 
Como os pontos quentes e gases foram detectados durante a fase de teste do equipamento em laboratório, serão descritos também os meios utilizados para predição e mitigação de eventuais pontos quentes que possam existir ainda na etapa de projeto no caso especifico do transformador GSU em análise. Ressaltando que em muitos casos, dependendo da localização dos pontos quentes e das características construtivas do transformador, a correção das falhas de projeto após a montagem do equipamento torna-se complexa e em alguns casos impraticáveis, pois requer a drenagem de todo óleo do tanque, alterações estruturais da parte ativa do transformador, entre diversos outros fatores que envolvem grande complexidade técnica e custos adicionais de fabricação.

\subsection{Passos no desenvolvimento de um transformador}

Conceitualmente, o processo ótimo para concepção e fabricação de equipamentos baseia-se em quatro pontos bem definidos e que devem sempre ser seguidos visando a otimização dos recursos e a qualidade do produto final. Estes passos são baseados nos checklists propostos pela ISO9001 (NBR ISO9001, 2015) em sua seção aplicadas aos projetos de engenharia de maneira geral.

1. Especificação das características gerais baseadas nas necessidades do cliente e parâmetros normativos

2. Execução do projeto inicial cobrindo as características solicitadas pelo cliente e condições previstas em normas técnicas e tecnologia do fabricante. Definição dos materiais, das distâncias dielétricas e magnéticas seguras e ótimas

3. Verificação e validação e modificações da solução por um corpo técnico habilitado a examinar criteriosamente os desenhos de fabricação e os dados de saída dos cálculos efetuados na concepção

4. Disponibilização das informações para os departamentos de compras de materiais, fabrica, departamentos de controle de qualidade, laboratório de ensaios e demais departamentos envolvidos.

Uma vez seguidos estes quatro pontos, o projeto está habilitado a ser construído, testado e finalmente entregue ao cliente.

A eventual necessidade de reparo em um transformador pode ter consequências ou impactos financeiramente catastróficos, dependendo do tipo de reparo e instante no qual o 
processo de fabricação se encontra. Por exemplo, a alteração da espessura de papel isolante no enrolamento na etapa de projeto tem custo, ou impacto, aproximadamente zero. No entanto se em virtude desta espessura um transformador sofra uma falha no ensaio o custo pode atingir milhares de reais para transformadores de grande potência, visto que haverá necessidade de desmontar toda a parte ativa, retirar os enrolamentos, produzir novo enrolamento, montar a unidade novamente, secar, e testar novamente. A seguir, na figura 12, é apresentado um diagrama que ilustra a ordem de grandeza do custo de uma alteração em função da etapa do processo.

Figura 12 - Ilustração do custo de uma falha versus etapa que se encontra o produto.

\section{Custo Relativo de impacto da alteração / modificação}

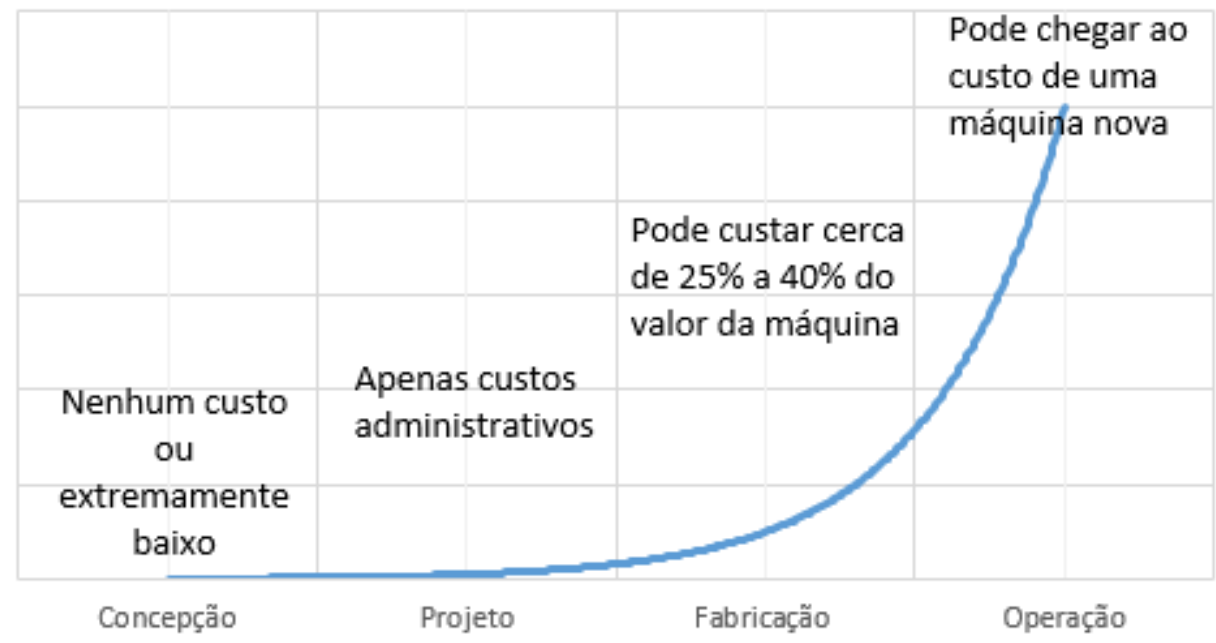

Fonte: Próprio Autor.

Por tais razões citadas, urge salientar sobre a importância de haver controles de qualidade eficientes e precisos em todas as etapas: Desde o projeto até a fabricação, da compra de material à entrega dos mesmos na fábrica passando pelo manuseio e instalação destes materiais no transformador. Por fim, na etapa final de produção, que contempla os testes finais na sala de testes até a instalação e comissionamento na planta do cliente. A aplicação com disciplina das ferramentas da qualidade estabelecidas pela ISO (International Organization for Standatization), como check-lists, pontos de inspeção controlados, dispositivos à prova de erros (poka-yoke), procedimentos e preceitos mostra-se como uma maneira muito eficiente de controlar a qualidade, no entanto são passíveis de falha como todo processo onde existe o envolvimento humano ou manual. 


\subsection{Cálculo analítico da temperatura nos pontos quentes}

O método analítico é desenvolvido a partir da Lei de Biot-Savart, qual descreve o campo magnético gerado a partir da corrente elétrica:

$$
\vec{H}=\oint \frac{I d \vec{L} \times \hat{a}_{r}}{4 \pi R^{2}}
$$

Onde:

I é a corrente elétrica em [A]

$d \vec{L}$ é o element diferencial de distância ao longo do caminho fechado de estudo

$\times \hat{a}_{r}$ é o produto vetorial com o versor de direção que une o elemento de corrente ao ponto no espaço que se deseja calcular o campo magnético.

$\mathrm{R}$ é a distância entre o elemento de corrente e a região que se está calculando o campo magnético

Levando em consideração o caso especifico da corrente através da bucha de baixa tensão de um transformador, tal como descrito na figura 6, a resolução da equação (1) pode ser descrita de forma simples em (2) (CARDOSO, 2011).

Dessa forma, a vista radial do flange/caneco de baixa tensão e do condutor, bem como a corrente e fluxo magnético, são descritos na figura 13. 
Figura 13 - Vista radial do flange de baixa tensão e condutor do transformador.

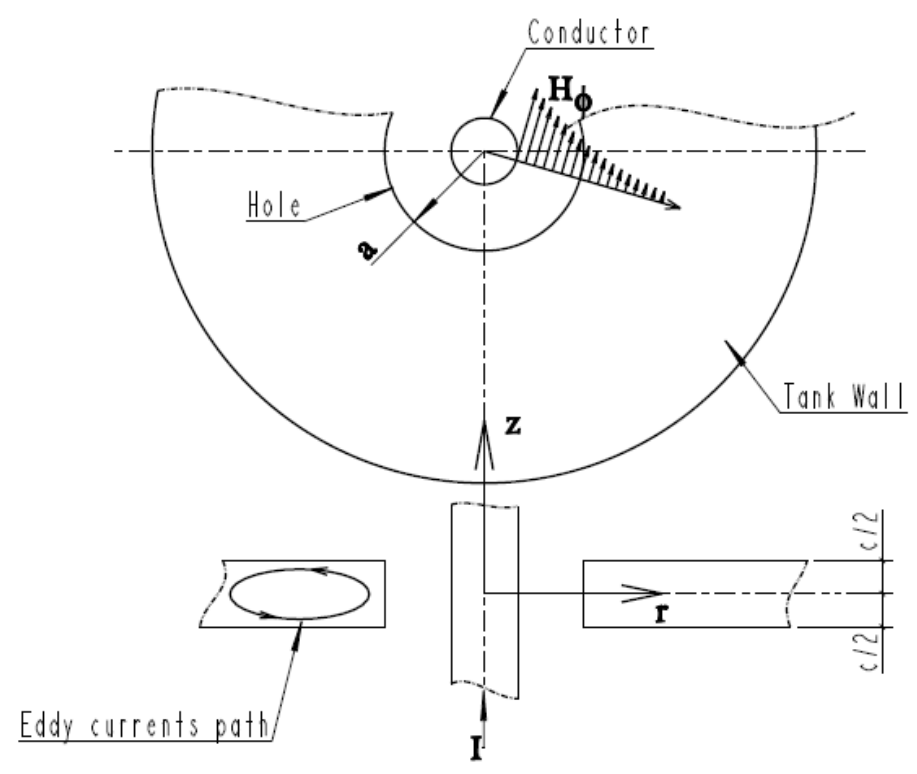

Fonte: MELO E CALIL, 2014.

$$
\vec{H}=\frac{I}{2 \pi r} \hat{\mathrm{a}}_{\varphi}
$$

O R da equação (1) tornou-se $r$, que é uma coordenada espacial cilíndrica. Sendo assim, ele ainda representa a distância entre o elemento de corrente e o ponto no qual desejase determinar o campo magnético. Com base na equação 2 e nas descrições da figura 13, verifica-se que a corrente $I$ encontra-se sobre o eixo $z$ (condutor) e $0 \leq r \leq \infty$. Ressaltando que de acordo com a figura 13, as seguintes condições de contorno são impostas para o caso do condutor através do flange no tanque do transformador:

$\vec{H}_{\varphi}=\frac{I}{2 \pi a}$ para $r=a$;

$\vec{H}_{\varphi}=0$ para $r=\infty \mathrm{e}$

$\vec{H}_{\varphi}=\frac{I}{2 \pi r}$ para $-\frac{c}{2} \leq z \leq+\frac{c}{2}$.

O parâmetro $r$ é definido como a distância radial do centro do cabo, $a$ é o raio do flange do tanque do transformador, $c$ é a espessura do tanque do transformador e o termo $I$ é a corrente através do condutor. Sabe-se que o rotacional do campo magnético é igual a densidade de corrente elétrica. Aplicando-se o rotacional novamente nesta afirmação, obtém- 
se a equação do campo magnético a partir do operador Laplaciano, mostrada na equação (3) a seguir.

$$
\nabla^{2} \vec{H}=j \omega \mu \sigma \vec{H}
$$

Sendo que $\mu$ é a permeabilidade magnética e $\sigma$ é a condutividade elétrica do meio atravessado pelo campo magnético gerado pela corrente que atravessa o condutor.

A solução da equação (3), no domínio do tempo e em coordenada cilíndricas, é dada como:

$$
\vec{H}_{(\vec{r}, t)}=\vec{H}(\vec{r}) e^{-j \omega t}
$$

A densidade de corrente $\vec{J}$ é responsável pelas perdas, que por sua vez, estão relacionadas diretamente à temperatura. Dessa forma, a densidade de corrente pode ser expressa em função do campo magnético $\vec{H}$ (CARDOSO, 2011):

$$
\vec{J}=\nabla \times \vec{H}=\left(\frac{1}{r} \frac{\partial H_{z}}{\partial \varphi}-\frac{\partial H_{\varphi}}{\partial z}\right) \hat{\mathrm{a}}_{r}+\left(\frac{\partial H_{r}}{\partial z}-\frac{\partial H_{z}}{\partial r}\right) \hat{\mathrm{a}}_{\varphi}+\frac{1}{r}\left(\frac{\partial\left(r H_{\varphi}\right)}{\partial r}-\frac{\partial H_{r}}{\partial \varphi}\right) \hat{\mathrm{a}}_{z}
$$

Na equação (5), $H_{z}$ e $H_{r}$ não variam na coordenada $\varphi$, assim como $H_{r}$ e $H_{z}$ não se alteram ao longo das coordenadas $z$ e $r$. Portanto, a equação (5) pode ser reduzida da forma descrita em (6).

$$
\vec{J}=\nabla \times \vec{H}=-\frac{\partial H_{\varphi}}{\partial z} \hat{\mathrm{a}}_{r}+\frac{1}{r} \frac{\partial\left(r H_{\varphi}\right)}{\partial r} \hat{\mathrm{a}}_{z}
$$

Uma das técnicas de resolução de equações diferenciais chamada de separação de variáveis pode ser aplicada neste equacionamento (HAYT W., 2009). Sendo $H_{\varphi}$ função de r e z, escreve-se a equação 6.1, na qual R é uma variável que só depende de (r) e Z só depende de $(\mathrm{z})$.

$$
H_{\varphi}=R(r) \cdot Z(z)
$$

Então aplicando-se (6.1) em (3) e impondo as condições de contorno apresentadas anteriormente, obtém-se a seguinte equação diferencial parcial (7): 


$$
\frac{1}{R}\left[\frac{1}{r} \frac{\partial y}{\partial r}\left(r \frac{\partial R}{\partial r}\right)-\frac{R}{r^{2}}\right]+\frac{1}{Z} \frac{\partial^{2} Z}{\partial z^{2}}=j \omega \mu \sigma
$$

O lado direito da equação (7) pode ser simplificada com um parâmetro que englobe as grandezas dos materiais como a condutividade, permeabilidade e frequência do sinal de corrente, conforme expresso na equação (8). Essa constante será importante na simplificação e na obtenção dos resultados desejados mais adiante.

$$
q=\sqrt{\frac{\omega \mu \sigma}{2}}
$$

Impondo as condições de contorno descritas anteriormente, para o caso especifico do flange, caneco e condutor da bucha de baixa tensão do transformador, a solução completa da equação (8) é expressa em termos trigonométricos (VECHIO, R.M. et al, 2009). Resolvendose (7) para $\mathrm{R}$ e Z, obtém-se $H_{\varphi}$. Neste último termo, que é de interesse, aplica-se outro rotacional e determina-se a densidade de corrente em (9).

$$
J_{r}=\frac{I q}{2 \pi r}\left[\frac{\alpha+j \beta}{\cosh \left(\frac{q c}{2}\right) \cos \left(\frac{q c}{2}\right)+j \operatorname{senh}\left(\frac{q c}{2}\right) \operatorname{sen}\left(\frac{q c}{2}\right)}\right]
$$

Sendo os termos real $\alpha$ e imaginário $\beta$, no numerador da equação (9), expressos em (10) e (11).

$$
\begin{aligned}
& \alpha=\operatorname{senh}(q \cdot z) \cos (q \cdot z)-\cosh (q \cdot z) \operatorname{sen}(q \cdot z) \\
& \beta=\cosh (q \cdot z) \cos (q \cdot z)+j \operatorname{senh}(q \cdot z) \operatorname{sen}(q \cdot z)
\end{aligned}
$$

As perdas no volume dos flanges, canecos e tanque do transformador podem ser calculadas integrando-se a densidade de corrente, tal como descrito na integral de volume na equação (12). Esta equação vem da segunda lei de Ohm.

$$
P_{v}=\int_{-\frac{c}{2}}^{\frac{c}{2}} \int_{0}^{2 \pi} \int_{a}^{b} \frac{\left|J_{r}\right|^{2}}{\sigma} r d r d \varphi d z
$$


A solução da integral de volume em (12) resulta em uma equação em função da espessura do tanque do transformador, permeabilidade magnética, condutividade e dimensões do equipamento, como descrito na equação (13).

$$
P_{v}=\frac{I^{2} q}{\pi \sigma} \ln \left(\frac{b}{a}\right)\left[\frac{\sinh (q c)-\sin (q c)}{\cosh (q c)-\cos (q c)}\right]
$$

A partir da potência dissipada nos flanges, canecos e tanque do transformador, é possível calcular a temperatura aproximada de forma analítica (MELO E CALIL, 2014):

$$
T_{w}=\frac{P_{v}}{h S}+T_{o}+T_{a}
$$

Os termos na equação (14) são: temperatura absoluta $T_{w}$; temperatura no óleo próximo a superfície do tanque $T_{o}$; temperatura ambiente $T_{a}$; superfície de troca de calor $S$; transferência de calor por convecção para o ar $h$.

O termo h é de suma importância no cálculo térmico, visto que ele é um parâmetro físico que descreve a convecção térmica que ira definir a temperatura final do objeto de estudo.

A equação 14.1 mostra o cálculo direto do coeficiente $\mathrm{h}$.

$$
h=\frac{N u \cdot k_{\text {oleo }}}{L_{C}}
$$

Onde:

h é o coeficiente de troca convectiva em $\mathrm{K} /\left(\mathrm{m}^{2} . \mathrm{K}\right)$

$\mathrm{Nu}$ é o número de Nusselt calculado com os parâmetros típicos do óleo.

$k_{\text {oleo }}$ é a condutividade térmica do óleo isolante

Lc é o comprimento característico no qual cresce a camada limite convectiva.

O número de Nusselt deve ser calculado iterativamente, visto que as grandezas físicas do óleo variam com a temperatura. Sendo assim, é necessário ter um critério de convergência, como por exemplo variações de $0.01 \operatorname{deg} C$ na temperatura calculada entre as iterações.

A literatura (KARSAI et al, 1987) contém tabelas completas com as características físicas do óleo dependentes da temperatura. 


\subsection{Método dos Elementos Finitos MEF}

Em diversas aplicações da engenharia, os fenômenos físicos são comumente modelados por meio de equações diferenciais, cuja solução analítica pode ser difícil de ser encontrada ou até mesmo impossível pelos métodos de solução analíticos existentes. A impossibilidade de se encontrar uma solução analítica pode ocorrer por diversos motivos, como equações diferenciais parciais não-lineares, que não podem ser linearizadas sem causar grandes erros nos resultados, região de solução complexa, condições de fronteira dependentes do tempo etc.

Diante desse fato, diversos métodos de solução numérica têm sido desenvolvidos, tais como (SADIKU, 1992): Método das Diferenças Finitas; Método Variacional; Método dos Momentos; Métodos dos Elementos de Fronteira e; Método dos Elementos Finitos (MEF).

O MEF, apesar de ser conceitualmente mais complexo que os métodos citados anteriormente, é mais versátil para lidar com problemas envolvendo geometrias e meios não-homogêneos. Desta forma, foi o método escolhido para ser utilizado neste trabalho, uma vez que o problema a ser resolvido possui tais características.

Nos parágrafos seguintes o MEF é descrito em detalhes, objetivando-se uma maior clareza na explicação das análises e solução propostas neste trabalho.

Segundo (SADIKU, 1992), a análise de qualquer problema pelo MEF é realizada, basicamente, através de quatros passos:

- Discretização da região em estudo por meio de um número finito de subregiões (elementos);

- Obter as equações que governam os fenômenos para cada elemento;

- Junção de todos os elementos na região;

- Solução do sistema de equações.

\subsubsection{Discretização da região em elementos}

O primeiro passo para aplicação do MEF é a discretização da região, em que se deseja calcular alguma grandeza, como o potencial elétrico, em várias partes com formas conhecidas, como mostra a Figura 14. 
Figura 14 - Região de solução discretizada em partes menores com formas conhecidas.

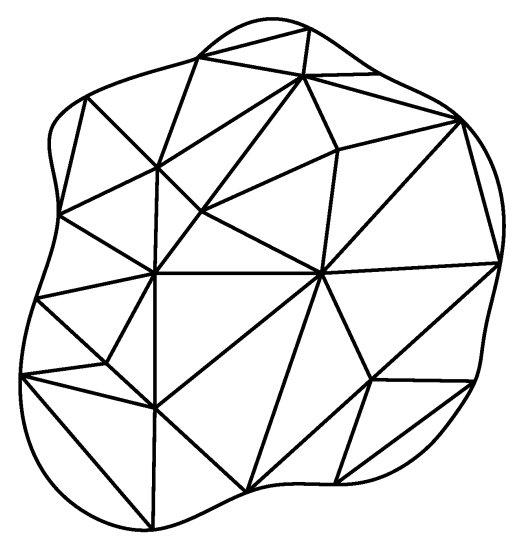

Fonte: Próprio Autor.

Algumas das formas conhecidas utilizadas são como as mostradas na Figura 15 a seguir.

Figura 15 - (a) Reta com dois nós (casos 1D). (b) Triângulo com três nós. (c) Retângulo com quatro nós. (d) Tetraedro com quatro nós (casos 3D).

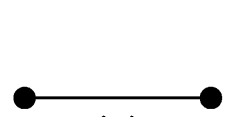

(a)

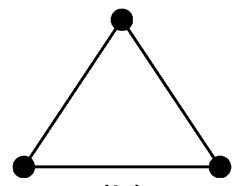

(b)

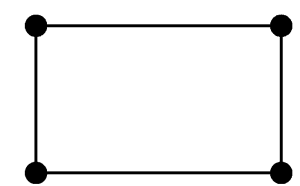

(c)

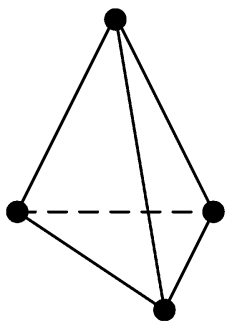

(d)

Fonte: Próprio Autor.

Cada forma mostrada na Figura 15 é um elemento, onde uma aproximação de uma grandeza (ex.: o potencial elétrico ou a temperatura) é determinada. Cada elemento é caracterizado por um número e por seus nós dentro da região de solução, conforme mostra a Figura 14. 


\subsubsection{Equações governantes dos elementos}

Tomando como exemplo a solução da equação de Laplace $\nabla^{2} V=0$, para o caso eletrostático, pode-se escrever uma equação para o potencial elétrico em um elemento da forma triangular (Figura 16). Se fosse a mesma situação para o campo térmico, o laplaciano seria $\nabla^{2} T=0$ para um caso estacionário no tempo. Embora o equacionamento deste trabalho é focado nos campos térmicos, a formulação eletrostática é apresentada com o intuito de manter a relação com a literatura referenciada (CARDOSO, 2016).

$$
V_{e}(x, y)=a+b x+c y
$$

Figura 16 - Elemento triangular típico

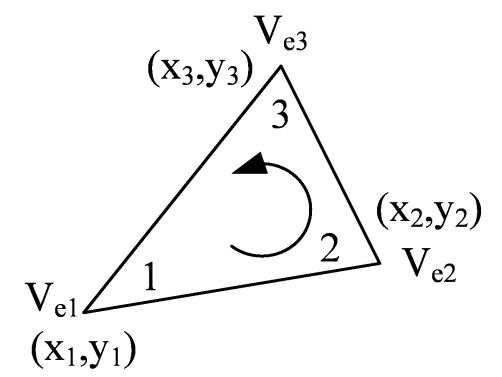

Fonte: Próprio Autor

Os potenciais nos pontos 1,2 e 3 da Figura 16 podem ser calculados da seguinte forma:

$$
\left[\begin{array}{c}
V_{e 1} \\
V_{e 2} \\
V_{e 3}
\end{array}\right]=\left[\begin{array}{lll}
1 & x_{1} & y_{1} \\
1 & x_{2} & y_{2} \\
1 & x_{3} & y_{3}
\end{array}\right]\left[\begin{array}{l}
a \\
b \\
c
\end{array}\right]
$$

Assim, os coeficientes $a, b$ e $c$ são calculados como:

$$
\left[\begin{array}{l}
a \\
b \\
c
\end{array}\right]=\left[\begin{array}{lll}
1 & x_{1} & y_{1} \\
1 & x_{2} & y_{2} \\
1 & x_{3} & y_{3}
\end{array}\right]^{-1}\left[\begin{array}{c}
V_{e 1} \\
V_{e 2} \\
V_{e 3}
\end{array}\right]
$$

Substituindo (16) em (15), pode-se determinar a tensão em qualquer ponto do elemento.

$$
V_{e}(x, y)=\left[\begin{array}{lll}
1 & x & y
\end{array}\right] \frac{1}{2 A}\left[\begin{array}{ccc}
\left(x_{2} y_{3}-x_{3} y_{2}\right) & \left(x_{3} y_{1}-x_{1} y_{3}\right) & \left(x_{1} y_{2}-x_{2} y_{1}\right) \\
\left(y_{2}-y_{3}\right) & \left(y_{3}-y_{1}\right) & \left(y_{1}-y_{2}\right) \\
\left(x_{3}-x_{2}\right) & \left(x_{1}-x_{3}\right) & \left(x_{2}-x_{1}\right)
\end{array}\right]\left[\begin{array}{l}
V_{e 1} \\
V_{e 2} \\
V_{e 3}
\end{array}\right]
$$


Onde $A$ é a área do elemento e pode ser calculada como:

$$
A=\frac{1}{2}\left|\begin{array}{lll}
1 & x_{1} & y_{1} \\
1 & x_{2} & y_{2} \\
1 & x_{3} & y_{3}
\end{array}\right|
$$

Outra forma de escrever (18) é:

$$
V_{e}(x, y)=\sum_{i=1}^{3} N_{i}(x, y) V_{e i}
$$

Onde os termos $N_{i}$ são conhecidos como funções de forma do elemento e possuem a seguinte propriedade:

$$
N_{i}\left(x_{j}, y_{j}\right)=\left\{\begin{array}{l}
1, \text { se } i=j \\
0, \text { se } i \neq j
\end{array}\right.
$$

O funcional corresponde a equação de Laplace é:

$$
W_{e}=\frac{1}{2} \int \varepsilon\left|\nabla V_{e}\right|^{2} d S
$$

Onde $\mathrm{W}_{\mathrm{e}}$ é a energia por unidade de comprimento associada ao elemento. Da equação (20):

$$
\nabla V_{e}=\sum_{i=1}^{3} \nabla N_{i} V_{e i}
$$

Substituindo-se (22) em (23) e colocando na forma matricial, tem-se que:

$$
W_{e}=\frac{1}{2} \varepsilon\left[V_{e}\right]^{t}\left[C^{e}\right]\left[V_{e}\right]
$$

A matriz $\left[C^{e}\right]$ é a matriz de coeficiente dos elementos, também conhecida como matriz de "rigidez". Os elementos da matriz de coeficiente são determinados da seguinte forma:

$$
C_{i j}^{e}=\int \nabla N_{i} \nabla N_{j} d S
$$

\subsubsection{Junção dos elementos}

Uma vez obtidas as equações de energia de cada elemento, obtêm-se a energia associada com a região de estudo somando-se a energia de cada um:

$$
W=\sum_{e=1}^{n} W_{e}=\frac{1}{2} \varepsilon[V]^{t}[C][V]
$$


Onde $[V]$ é o vetor de tensões em cada um dos nós (vértices dos elementos) da região de estudo e $[C]$ é a matriz de coeficientes global.

\subsubsection{Solução do sistema de equações}

A equação 26 pode ser resolvida por meio de diversos métodos, um dos métodos é o da matriz de banda.

Tomando-se (26), a mesma pode ser reorganizada de forma a dispor os nós com potencial desconhecido nas primeiras linhas e os nós com os potenciais conhecidos nas linhas seguintes no vetor de potenciais:

$$
W=\frac{1}{2} \varepsilon\left[\begin{array}{ll}
V_{d} & V_{c}
\end{array}\right]\left[\begin{array}{ll}
C_{d d} & C_{d c} \\
C_{c d} & C_{c c}
\end{array}\right]\left[\begin{array}{l}
V_{d} \\
V_{c}
\end{array}\right]
$$

Onde os índices $d$ e $c$ significam desconhecido e conhecido, respectivamente.

A solução de (27) consiste em determinar os valores de $V_{d}$ que minimizam a energia W. Ou seja:

$$
\frac{\partial W}{\partial V_{k}}=0
$$

Uma vez que os valores de $V_{c}$ são conhecidos e constantes, basta aplicar (28) aos potenciais desconhecidos em (27). Desta forma:

$$
\left[V_{d}\right]=-\left[C_{d d}\right]^{-1}\left[C_{d c}\right]\left[V_{c}\right]
$$

Portanto, a solução do sistema, ou seja, os potenciais ou temperaturas em cada nó da região em estudo, é determinada. Para se obter o potencial em outros pontos da região em estudo, ou seja, não somente nos vértices dos elementos, basta utilizar (20). Ainda, é possível determinar o campo elétrico ou o gradiente térmico dentro da região por meio de (23).

\subsection{Detecção e análise dos gases}

O dispositivo utilizado na análise proposta trata-se de um transformador de potência novo, desenvolvido por um fabricante mundialmente conhecido do setor elétrico para integrar um parque eólico ao sistema de transmissão em $230 \mathrm{kV}$. Durante os testes laboratoriais, foi detectada a formação de gases no interior do equipamento através de amostras de óleo periódicas que são extraídas durante os ensaios de aceitação em fábrica - mais 
especificamente o ensaio de aquecimento. Por se tratar de pequena concentração de gases, o relé de gases não chega a atuar, contudo a cromatografia gasosa se mostra a melhor ferramenta para avaliar a condição do óleo isolante. Dada a existência, principalmente, de $\mathrm{C}_{2} \mathrm{H}_{4}$, o qual não é previsto, cabe uma análise cautelosa. Dessa forma, uma metodologia de análise foi elaborada para diagnosticar a origem deste gás e solucionar o defeito. Tal metodologia é composta de métodos computacionais (MEF), medições e análises químicas do óleo para identificação dos gases e falha ocorrida.

Todos os parâmetros de suportabilidade dielétrica, transferência térmica, vida útil, dentre outros são estabelecidos baseados na presença de gases e impurezas no óleo, ou seja, o óleo é tido como apto para ser utilizado em transformadores de alta tensão após passarem pelos processos de desgaseificação e filtragem. Tal metodologia é ilustrada resumidamente na figura 17.

O óleo deixa o reservatório, que em geral trata-se do próprio tanque do transformador, passando por um processo de pré-filtragem (1) e pela bomba de sucção (2). Em sequencia, o óleo é aquecido por um banco de resistências (3), seguindo para o filtro principal (4) para logo então adentrar o tanque de desgaseificação (5), que se encontra sob vácuo gerado pela bomba principal (6). Uma bomba de vácuo auxiliar (7) é utilizada em paralelo com o tanque de desgaseificação e o tanque do transformador, garantindo a manutenção do vácuo durante o processo. O vácuo é necessário para remoção dos gases, a partir do vapor gerado pelo aquecimento do óleo no tanque de desgaseificação. Os filtros removem as partículas em suspensão, diretamente relacionadas com a rigidez dielétrica do óleo. 
Figura 17 - Planta de tratamento de óleo (desgaseificação e filtragem).

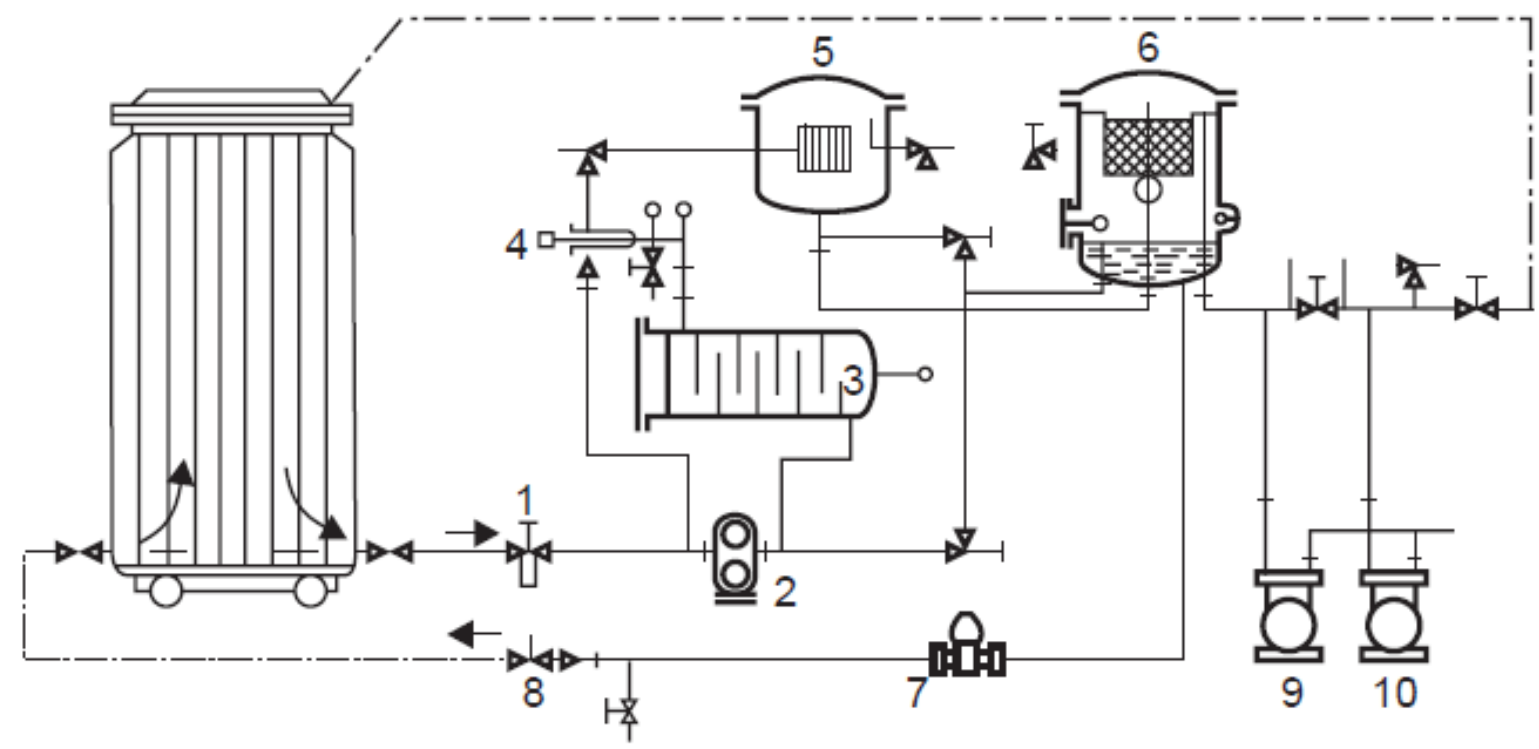

Fonte: WADWHA (2007).

Antes dos ensaios dielétricos, são retiradas amostras de óleo isolante para se conhecer o estado inicial desse fluído (após o processo de desgaseificação e filtragem). São realizadas análises físico-químicas do óleo, visto que os resultados obtidos nos ensaios dielétricos geralmente não são suficientes para diagnosticar com exatidão as possíveis falhas no interior dos transformadores. Dessa forma, a análise do desempenho do transformador é dada a partir da associação de resultados de testes elétricos e monitoramento das características físicoquímicas do óleo, estabelecendo um histórico da integridade estrutural e operacional do dispositivo ao longo da batelada de testes.

As amostras de óleo são coletadas a partir de válvulas localizadas no tanque e na parte superior do transformador. Via de regras, estas amostras devem ser retiradas na parte superior e inferior do tanque e analisadas individualmente, dessa forma, torna-se possível inferir sobre a localização física do defeito no interior do transformador. Além disso, dado o grande volume de óleo (aproximadamente $100 \mathrm{~m}^{3}$ em transformadores de grande porte), os gases levam algum tempo para se diluírem de forma homogênea no óleo do transformador.

A concentração de gases, obtida por meio de cromatografia, é descrita na tabela 2. 
Tabela 2 - Concentração dos gases.

\begin{tabular}{|c|c|c|c|c|c|c|c|c|c|c|c|}
\hline Amostra & $\begin{array}{c}\text { Oxigênio } \\
\text { O2 }\end{array}$ & $\begin{array}{c}\text { Nitrogênio } \\
\text { N2 }\end{array}$ & $\begin{array}{c}\text { Diox. } \\
\text { Carbono } \\
\text { CO2 }\end{array}$ & $\begin{array}{c}\text { Hidrog. } \\
\text { H2 }\end{array}$ & $\begin{array}{c}\text { Monox. } \\
\text { Carbono }\end{array}$ & $\begin{array}{c}\text { Metano } \\
\text { CH4 }\end{array}$ & $\begin{array}{c}\text { Etano } \\
\text { C2H6 }\end{array}$ & $\begin{array}{c}\text { Etileno } \\
\text { C2H4 }\end{array}$ & $\begin{array}{c}\text { Acetileno } \\
\text { C2H2 }\end{array}$ & Observação & Tempo \\
\hline$\#$ & {$[\mathrm{ppm}]$} & {$[\mathrm{ppm}]$} & {$[\mathrm{ppm}]$} & {$[\mathbf{p p m}]$} & {$[\mathrm{ppm}]$} & {$[\mathrm{ppm}]$} & $\mathbf{[ p p m}]$ & {$[\mathrm{ppm}]$} & {$[\mathrm{ppm}]$} & & \\
\hline $\mathbf{1}$ & 1219 & 3240 & 6 & 1 & $\mathrm{nd}$ & 0,1 & $\mathrm{nd}$ & $\mathrm{nd}$ & $\mathrm{nd}$ & Antes de todos ensaios & 0 \\
\hline $\mathbf{2}$ & 1266 & 3338 & 9 & 1 & $\mathrm{nd}$ & 0,1 & $\mathrm{nd}$ & $\mathrm{nd}$ & $\mathrm{nd}$ & Após ensaios dielétricos & 33,5 \\
\hline $\mathbf{3}$ & 1507 & 3393 & 11 & 3 & 1 & 0,1 & $\mathrm{nd}$ & $\mathrm{nd}$ & $\mathrm{nd}$ & Após estabilização ONAN & 45,5 \\
\hline $\mathbf{4}$ & 1550 & 3567 & 36 & 13 & 5 & 0,2 & 0,1 & 0,1 & $\mathrm{nd}$ & Após estabilização ONAF & 51,5 \\
\hline
\end{tabular}

Fonte: Próprio Autor.

A primeira amostra trata-se do óleo em seu estado inicial, antes dos ensaios dielétricos. Quantidades pequenas de $\mathrm{CH}_{4}$ e $\mathrm{H}_{2}$ estão presentes nesta amostra, contudo com quantidades mínimas na ordem de $0.1 \mathrm{ppm}$ de $\mathrm{CH}_{4}$ e $1 \mathrm{ppm}$ de $\mathrm{H}_{2}$. Essas pequenas concentrações podem ser resultantes de pequenas oscilações de medição ou mesmo da própria reação do óleo junto à superfície interna do tanque do transformador, peças metálicas de inox, verniz, cola, tinta interna, resíduos zincados dos radiadores, conforme abordado anteriormente na seção 2.3 .

A segunda amostra coletada foi obtida após a realização dos ensaios dielétricos, como impulso atmosférico, impulso de manobra, tensão induzida com medição de descargas parciais e tensão aplicada. Observa-se a integridade do óleo nesta segunda amostra, confirmando-as assim a integridade das isolações e do óleo isolante após tais ensaios.

A terceira amostra na tabela foi extraída após a estabilização da temperatura com o transformador ligado com potência de operação equivalente a $60 \%$ da potência nominal, de forma a testar o estágio ONAN (Óleo natural, Ar natural), sem o funcionamento dos ventiladores. Esta estabilização é definida quando a variação de temperatura no óleo é menos de $1,0{ }^{\circ} \mathrm{C}$ a cada três horas. Nessa ocasião, a amostra de óleo não apresentou nenhuma variação significativa, visto que a variação da quantidade de $\mathrm{H}_{2}$ e $\mathrm{CH}_{4}$ é desprezível. Quantidades da ordem de $0.1 \mathrm{ppm}$ de $\mathrm{CH}_{4}$ podem ser desprezadas.

A manutenção da parte ativa do transformador após a fabricação é um processo complexo e deve ser realizada com cautela. Torna-se importante ressaltar que a formação de pequenas concentrações de gases, em especialmente o $\mathrm{H}_{2}$, pode ser resultante da reação química entre o óleo e a própria tinta, peças de aço inox e até metais galvanizados utilizados na parte ativa. Mesmo a limpeza dos radiadores deve ser cautelosamente verificada quando uma análise cromatográfica é realizada. Muitas vezes, durante o próprio processo de fabricação do equipamento, alguma quantidade de $\mathrm{H}_{2}$ é gerada, o que não necessariamente indica um defeito. No caso estudado, a variação de 2,0 ppm não indica um problema de forma 
direta. Recomenda-se manter o transformador ligado por mais tempo para verificar se a concentração dos gases se altera.

$\mathrm{O} \mathrm{CH}_{4}$ é um hidrocarboneto leve e é gerado em temperaturas por volta de $120{ }^{\circ} \mathrm{C}$ do óleo (IEEE, 2008). Nos processo convencionais de desgaseificação, conforme mencionado anteriormente, existe uma resistência de aquecimento e uma bomba de óleo (figura 13) que podem ocasionar dois fenômenos:

a. O próprio calor do desgaseificador pode gerar gases $\left(\mathrm{H}_{2}\right.$ e $\left.\mathrm{CH}_{4}\right)$ e consequentemente induzir interpretações errôneas a partir dos resultados da cromatografia;

b. Bombas do tipo rotor imerso em óleo, onde o fluído circula em contato com os enrolamentos e com o rotor, podem gerar gases devido a falhas na isolação interna, centelhamento ou mesmo superaquecimento dos enrolamentos, resultando na formação adicional de gases no óleo.

Dessa forma, conclui-se que o próprio processo de desgaseificação do óleo pode gerar gases combustíveis, fato que explica a presença de pequenas quantidades de $\mathrm{H}_{2}$ e $\mathrm{CH}_{4} \operatorname{logo}$ nas primeiras amostras do óleo, antes mesmo dos primeiros ensaios dielétricos.

A quarta amostra e análise dos gases, realizada após a estabilização da temperatura com o transformador à plena carga e último estágio de refrigeração ONAF, foi detectada variação na quantidade de $\mathrm{H}_{2}$, monóxido de carbono, $\mathrm{C}_{2} \mathrm{H}_{4}$ e $\mathrm{C}_{2} \mathrm{H}_{6}$, como descrito na tabela. Estes dois últimos gases claramente indicam a presença de alguma anomalia no transformador. Embora a quantidade seja ínfima (0.1 ppm), estes gases necessitam de maior quantidade de energia para se formar. A detecção de $0.1 \mathrm{ppm}$ exige cromatógrafos precisos e mão de obra especializada visto ser um range de medida fora dos valores normais do dia a dia.

A presença de monóxido de carbono indica que pode ou não existir ponto quente envolvendo a celulose dos enrolamentos (IEEE, 2008). Contudo, investigações mais apuradas devem ser realizadas para conclusões mais precisas e conclusivas baseando-se no histórico do transformador mesmo ainda na fábrica. De acordo com a norma técnica, a geração de gases combustíveis está abaixo do limite (IEEE, 2008), no entanto a presença de C2H4 e C2H6 não deve ser negligenciada. Dessa forma, uma segunda análise é realizada com base na geração de gases em ppm por hora, tal como descrito na tabela 3. 
Tabela 3 - Evolução na formação dos gases.

\begin{tabular}{|c|c|c|c|c|c|c|c|c|}
\hline \multicolumn{7}{|c|}{ Geração de gases combustíveis após Ensaio de aquecimento } \\
\hline $\begin{array}{c}\text { Oxigênio } \\
\text { O2 }\end{array}$ & $\begin{array}{c}\text { Nitrogênio } \\
\text { N2 }\end{array}$ & $\begin{array}{c}\text { Diox. } \\
\text { Carbono } \\
\text { CO2 }\end{array}$ & $\begin{array}{c}\text { Hidrog. } \\
\text { H2 }\end{array}$ & $\begin{array}{c}\text { Monox. } \\
\text { Carbono }\end{array}$ & $\begin{array}{c}\text { Metano } \\
\text { CH4 }\end{array}$ & $\begin{array}{c}\text { Etano } \\
\text { C2H6 }\end{array}$ & $\begin{array}{c}\text { Etileno } \\
\text { C2H4 }\end{array}$ & $\begin{array}{c}\text { Acetileno } \\
\text { C2H2 }\end{array}$ \\
\hline$[\mathrm{ppm} / \mathrm{h}]$ & {$[\mathrm{ppm} / \mathrm{h}]$} & {$[\mathrm{ppm} / \mathrm{h}]$} & {$[\mathrm{ppm} / \mathrm{h}]$} & {$[\mathrm{ppm} / \mathrm{h}]$} & {$[\mathrm{ppm} / \mathrm{h}]$} & {$[\mathrm{ppm} / \mathrm{h}]$} & {$[\mathrm{ppm} / \mathrm{h}]$} & {$[\mathrm{ppm} / \mathrm{h}]$} \\
\hline $\mathrm{na}$ & $\mathrm{na}$ & $\mathrm{na}$ & 0,66 & 0,22 & $<0,006$ & $<0,006$ & $<0,006$ & $\mathrm{nd}$ \\
\hline
\end{tabular}

Fonte: Próprio Autor.

De acordo com a norma técnica estabelecida pelo IEEE e IEC, índices de formação de $\mathrm{H}_{2}$ em torno de $0,7 \mathrm{ppm} / \mathrm{h}$ indicam anomalias no transformador, porém não se pode afirmar a real existência de problemas baseado apenas neste indicador. Ressaltando que a formação de $\mathrm{H}_{2}$ e $\mathrm{CH}_{4}$ se dá em temperaturas acima de $120^{\circ} \mathrm{C}$, enquanto que $\mathrm{C}_{2} \mathrm{H}_{6}, \mathrm{C}_{2} \mathrm{H}_{4}$ e $\mathrm{C}_{2} \mathrm{H}_{2}$ são formados em temperaturas superiores (IEEE, 2008; IEC, 1999). Dessa forma, a análise dos gases indica a presença de pontos quentes no interior do transformador sem a existência de descargas elétricas com alta dissipação de energia. No entanto, análises térmicas adicionais devem ser realizadas para detectar a localização desses prováveis pontos quentes.

\subsection{Cálculo da temperatura utilizando MEF}

Embora a abordagem analítica, descrita a partir das equações eletromagnéticas de Maxwell, apresenta sólido embasamento teórico, algumas aproximações são necessárias. O método de cálculo analítico não considera adequadamente a saturação do ferro e o efeito da proximidade de alguns componentes do transformador (BIRÓ et al., 2012). Naturalmente, tais aproximações levam a algumas imprecisões no método, que serão analisadas em função dos resultados apresentados ainda nesse capítulo.

Dentre todas as ferramentas computacionais para o cálculo dos pontos quentes, o MEF é sem dúvidas o mais adequado para a abordagem proposta. Tal método leva em consideração todos os aspectos físicos, características dos materiais utilizados nas partes envolvidas do transformador, geometria e interação entre os campos elétricos e magnéticos (CARDOSO, 2016). Neste contexto, o MEF é aplicado nos cálculos das temperaturas envolvendo parte do tanque do transformador, flanges, canecos, condutores e bucha de baixa tensão do transformador. O modelo tridimensional da parte do transformador, com flanges e condutores das buchas de baixa tensa, foi desenhado em CAD, como descrito na figura 18. 
Figura 18 - Modelo em CAD do tanque, flange e condutores.

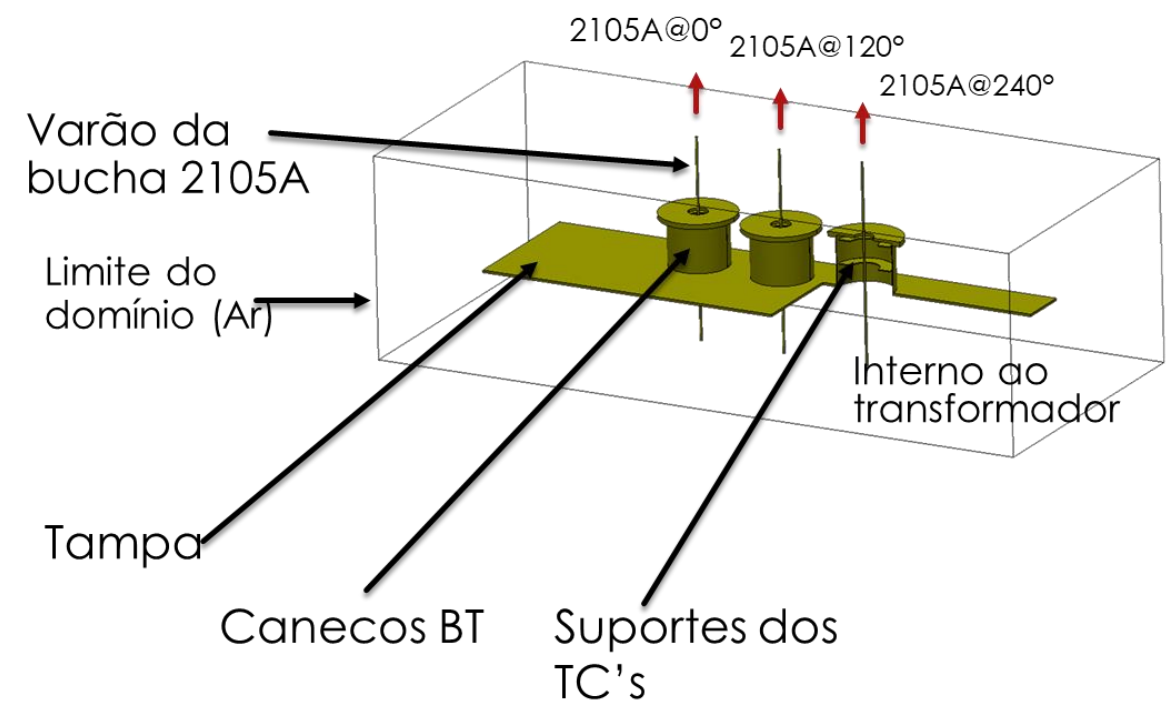

Fonte: Próprio Autor.

Os flanges, tanque e condutores da figura 18 são modelados com base nas características construtivas do transformador GSU descritos anteriormente. Na sequência, a estrutura é discretizada em uma malha tetraédrica, figura 19. Cada vértice dos tetraedros é identificado por sua posição e recebem as propriedades físicas dos materiais, condições de contorno eletromagnéticas, tal como mostrado na figura 18.

Figura 19 - Renderização da estrutura tridimensional.

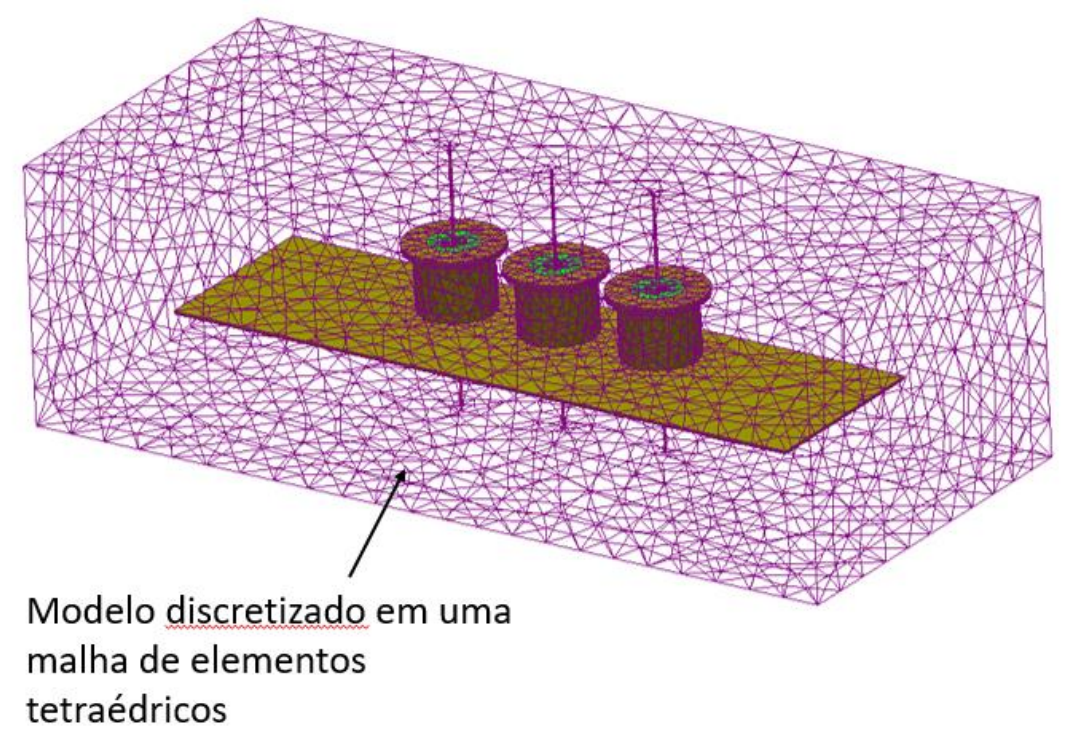

Fonte: Próprio Autor. 
As propriedades eletromagnéticas de cada material da estrutura devem ser determinadas durante a discretização, tal como: permeabilidade magnética e condutividade elétrica. Em sequência, o mapeamento da temperatura na estrutura do transformador é calculado fazendo-se uso de um multiphysics software.

A transferência de calor é realizada principalmente por convecção, dessa forma, o coeficiente de transferência de calor deve ser considerado (CALIL et al., 2012). O coeficiente de transferência de calor pode ser obtido de forma analítica nas literaturas (INCROPERA, 20017) ou por meio de programas computacionais aplicados à análise da dinâmica dos fluidos Computational Fluid Dynamics (CFD). Ressaltando-se que a transferência de calor por convecção se dá através do ar e óleo do transformador. Dessa forma, o software utilizado na resolução da malha da estrutura deve levar em consideração as perdas induzidas pelo efeito eletromagnético em função das correntes elétricas e a transferência de calor através do óleo e do ar (CRETU E SCHNEIDER, 2009).

\subsection{Análise termográfica do transformador}

Uma vez que a cromatografia gasosa indicou a presença de hidrocarbonetos e/ou óxidos de carbono, o próximo passo para o completo diagnóstico do defeito é o mapeamento térmico das partes externas do transformador. A análise térmica externa do transformador é possível por meio de termografia infravermelha, sem a utilização de sensores, tais como termopares e termoresistências. Tal técnica representa uma forma não invasiva para detecção de defeitos resultantes de pontos quentes nos transformadores.

Os resultados obtidos por meio de análise termográfica por radiação infravermelha são descritos nas figuras 20 e 21, referentes à parte superior esquerda e direita do transformador durante o ensaio, logo após estabilização do óleo em ONAF2. Ressaltando que H1, H2 e H3 são os termos utilizados para indicar as buchas de alta tensão 1,2 e 3, respectivamente. De maneira análoga, os termos X1, X2 e X3 indicam as buchas de baixa tensão 1, 2 e 3, respectivamente. 
Figura 20 - Termovisão lado esquerdo (bucha inclinada H1 e central H2).
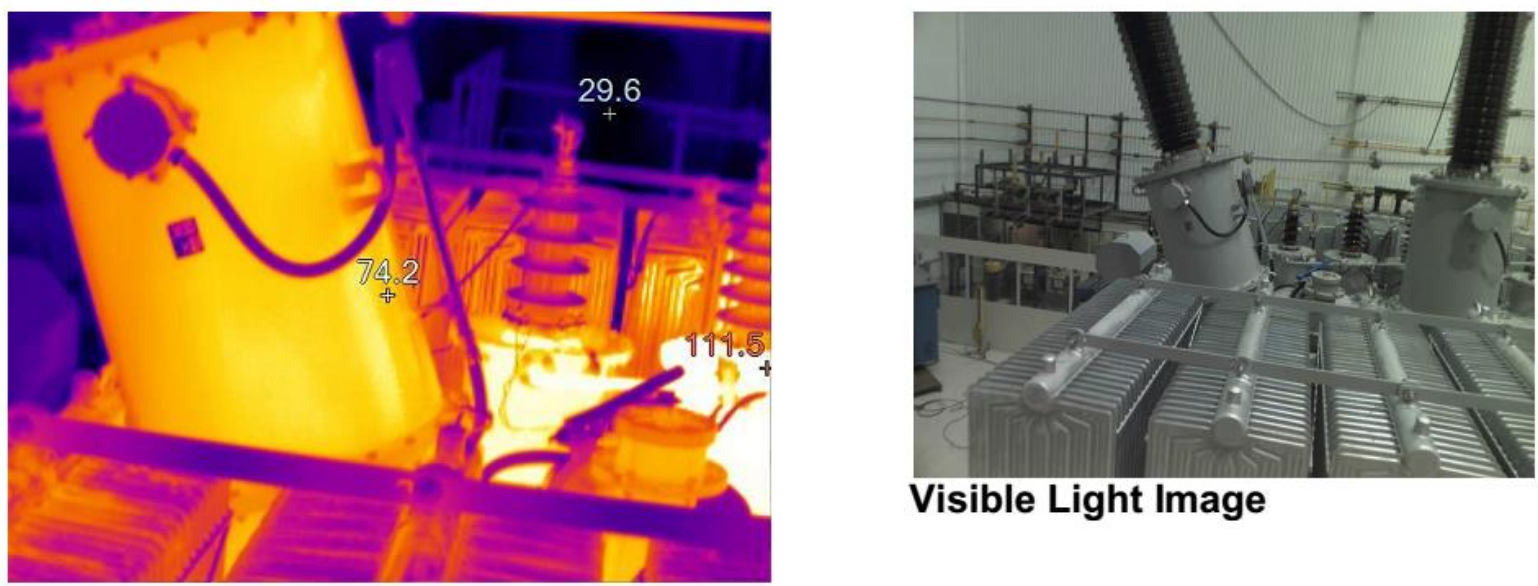

Visible Light Image

Fonte: Próprio Autor.

Figura 21 - Termovisão do lado direito (bucha inclinada H3 e central H2).
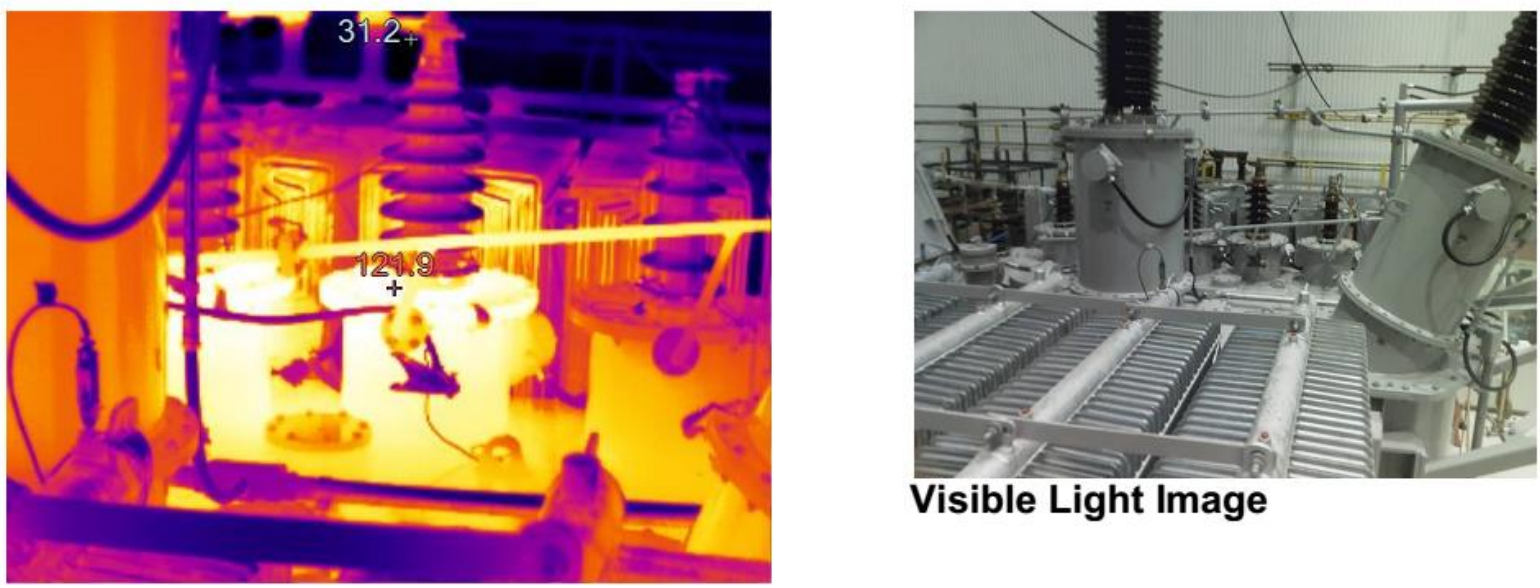

Visible Light Image

Fonte: Próprio Autor.

A termovisão da figura 21 descreve temperaturas por volta de $122^{\circ} \mathrm{C}$ na superfície dos flanges e canecos de fixação das buchas. Embora temperaturas por volta de 100 a $130{ }^{\circ} \mathrm{C}$ não ofereçam riscos diretos na operação do transformador, indicam que existem falhas na construção do transformador e pontos de sobreaquecimento internos. A operação continua na faixa de temperatura observada irá resultar em danos na pintura, falhas na vedação dos tanques e principalmente na formação continua de gases combustíveis, fatores que podem levar a falha do equipamento e até mesmo riscos de recursos humanos. Em temperaturas desta ordem devem ser utilizadas gaxetas de um material conhecido como Viton, capaz de suportar temperaturas mais elevadas do que as convencionais de nitrílica. 
As temperaturas registradas por termovisão mostram que os pontos quentes detectados podem resultar na geração de $\mathrm{H}_{2}$ e $\mathrm{CH}_{4}$, tal como enfatizado nas descrições normativas do IEEE e IEC e ainda detectados previamente na análise dos gases por cromatografia.

As medições realizadas na analise termográfica mostram as temperaturas externas no tanque, flanges e canecos do transformador. Para um estudo mais apurado sobre partes internas envolvidas no sobreaquecimento observado, torna-se necessário uma análise detalhada em função das características físicas e construtivas tanto das peças externas como internas localizadas nos pontos quentes indicados na análise termográfica. Dessa forma, propõe-se uma análise detalhada dos flanges, tanque, canecos e suportes dos transformadores de corrente (TCs) conectados logo na base das buchas, para fim de medição.

\subsection{Análise térmica pelo MEF e método analítico}

A parte superior do tanque, incluindo os canecos, flanges e suporte dos TCs, conectados na parte interna do transformador, são modeladas fazendo uso do MEF, levandose em conta suas características eletromagnéticas, físicas e geométricas. Dessa forma, pode-se obter o perfil de temperatura tanto da parte externa do transformador, tal como verificado na análise termográfica, quanto dos elementos internos do tanque.

Os elementos da parte superior do transformador, junto às buchas de baixa tensão, foram modelados em 3D, tal como descrito na seção 4.4. As características físicas e eletromagnéticas foram levadas em conta durante a discretização do modelo CAD.

A temperatura junto à base dos flanges foi calculada também fazendo uso do método analítico descrito na seção 4.2, em função da potência dissipada nos flanges e canecos de suporte das buchas de baixa tensão.

O perfil de temperatura obtido por meio do MEF, tanto para peças na superfície do tanque quanto para peças que compões a parte interna dos flanges e canecos, é mostrado em detalhes na figura 22.

Observam-se temperaturas elevadas nos suportes dos TCs, entre 135 a $143{ }^{\circ} \mathrm{C}$. Também se observa que o cálculo computacional coincide com o que fora medido na termografia, aproximadamente $121^{\circ} \mathrm{C}$ na parte superior dos canecos. Esses resultados estão em consonância com os valores obtidos por meio da análise termográfica descrita nas figuras 20 e 21.

Vale observar também que junto aos suportes dos TCs, existem materiais compostos por pressboard que é à base de celulose. Dessa forma, o aquecimento em $140^{\circ} \mathrm{C}$ do suporte 
dos TCs, como mostrado na figura 22, resulta na formação de monóxido de carbono, como descrito na análise dos gases realizada anteriormente. Urge também salientar, que a isolação sólida de pressboard convencional e estrutural não é termoestabilizada e dimensionada para operar em temperaturas absolutas acima de $110^{\circ} \mathrm{C}$.

Figura 22 - Perfil de temperatura calculado por meio do MEF.

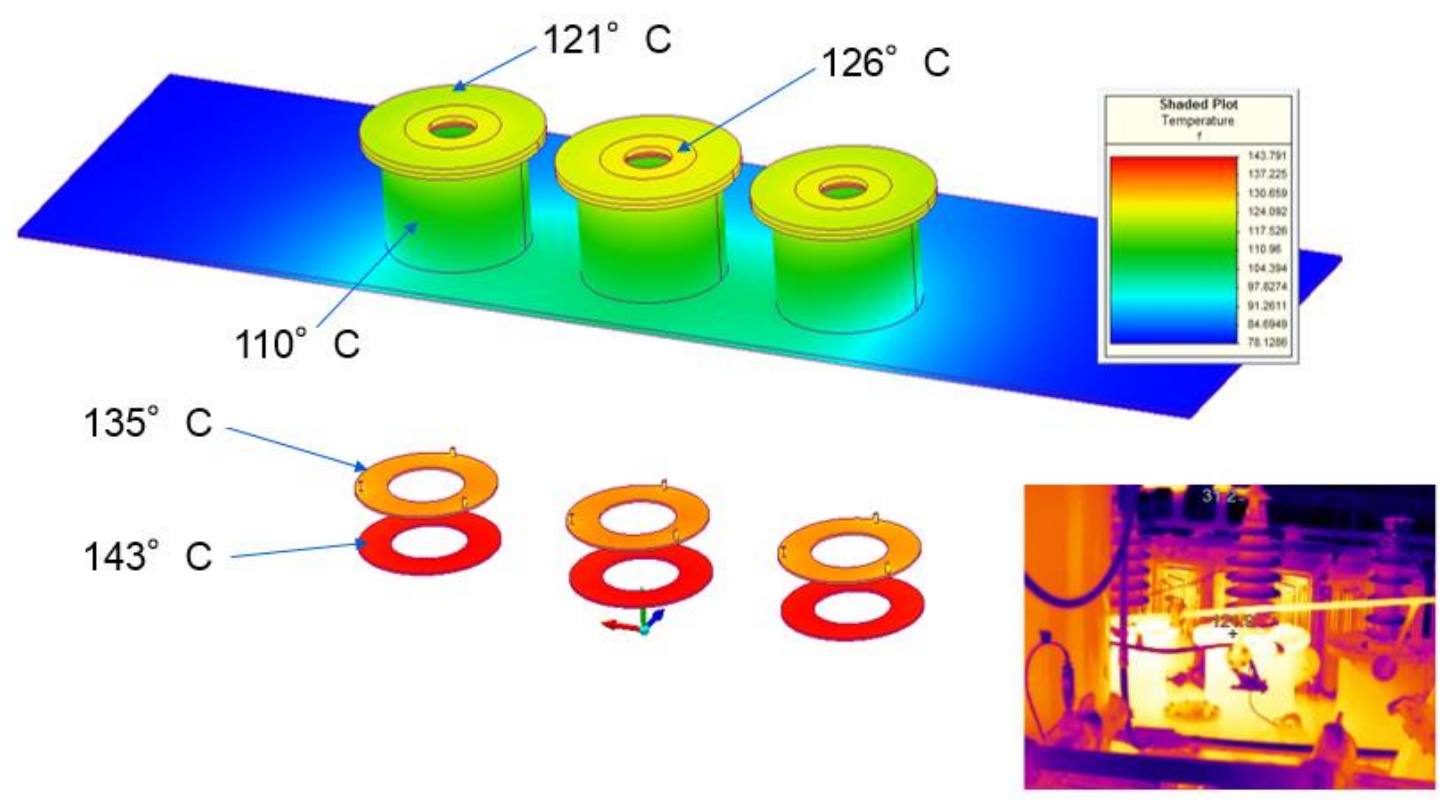

Fonte: Próprio Autor.

Após averiguar sobre as causas do excessivo aquecimento na parte superior do transformador, junto às buchas de baixa tensão, verificou-se que os pontos quentes estavam no suporte dos TCs, logo abaixo dos flanges e canecos das buchas de baixa tensão. Houve uma falha na seleção do material na usinagem dos suportes dos TCs. Eles foram desenvolvidos com material ferromagnético ao invés do que fora especificado (material não magnético), gerando sobreaquecimento devido à indução de correntes parasitas devido ao fluxo de dispersão do núcleo do transformador. Tal constatação foi inicialmente possível devido à detecção de gases no óleo do transformador, localização dos pontos quentes fazendose uso de análise termográfica e por fim, aplicação do MEF para mapear a origem dos pontos quentes no interior do transformador de forma não invasiva, em função apenas das características físicas e eletromagnéticas dos elementos que compões a parte superior do transformador, próximos das buchas de baixa tensão. Esta situação ocorre, pois, a região de interesse é inacessível, pois está dentro dos canecos das buchas. 
De forma complementar, com base no método analítico desenvolvido na seção 4.2, foi possível calcular a temperatura aproximada dos pontos quentes, sem a utilização de métodos computacionais. A tabela 4 compara as temperaturas máximas obtidas por meio de medições e pelo método analítico e dos elementos finitos, bem como as perdas em Watts.

Tabela 4 - Cálculo e medição da temperatura nos pontos quentes

\begin{tabular}{|c|c|c|c|}
\hline Método & Local & Perdas [W] & Temperatura [degC] \\
\hline \multirow{2}{*}{ Medição } & Flange externa & - & 126 \\
\cline { 2 - 4 } & Suporte de TC & - & - \\
\hline \multirow{2}{*}{ Analítico } & Flange externa & 508 & 132 \\
\cline { 2 - 4 } & Suporte de TC & 231 & 145 \\
\hline \multirow{2}{*}{ MEF } & Flange externa & 522 & 126 \\
\cline { 2 - 4 } & Suporte de TC & 238 & 143 \\
\hline
\end{tabular}

Fonte: Próprio Autor.

Os resultados calculados com o método analítico foram obtidos por meio das equações (5), (13) e (14). Embora o método analítico e o MEF apresentem procedimentos de cálculo totalmente diferentes, verifica-se que ambos resultam em temperaturas muito próximas dos valores medidos.

Neste caso, as dimensões dos flanges são:

i. Flanges externos: $500 / 130 \mathrm{~mm}$ por $18 \mathrm{~mm}$ de espessura;

ii. Flanges suportes de TC: $350 / 190 \mathrm{~mm}$ por $6.3 \mathrm{~mm}$ de espessura.

Dessa forma, a metodologia utilizada no diagnóstico do defeito no transformador analisado pode ser dividida em algumas etapas. Primeiramente foi detectada a existência de hidrocarbonetos e óxidos de carbono no óleo, a partir das amostras periódicas de óleo. Em sequência, foram identificados os gases existentes no óleo e com base na literatura técnica, pode-se estimar o tipo de defeito ocorrido no transformador (método do gás chave). Após a detecção, identificação e estimação da eventual falha no interior do equipamento, os pontos quentes foram localizados por meio de análise termográfica por radiação infravermelha. Por fim, de forma a determinar com exatidão quais peças estão sobreaquecendo no interior do transformador, o MEF foi utilizado na modelagem do local onde os pontos quentes foram localizados, em função das características físicas, estruturais e eletromagnéticas de cada parte modelada. Detectou-se finalmente que os flanges que suportam mecanicamente os TCs das 
buchas de baixa tensão estavam sobreaquecendo devido à troca indevida do material utilizado na fabricação dessas peças.

Uma vez identificados os elementos que originaram os pontos quentes no interior do transformador, a solução direta e menos invasiva é substituir essas peças da forma menos invasiva possível através de processos mecânicos de corte, lixamento, ressoldagem e pintura. Desta forma, os flanges de suporte dos TCs foram substituídos por outros compostos por material não magnético, mais especificamente o aço inox.

\subsection{Análise térmica e dos gases após o reparo}

Logo então, antes da realização de novos testes elétricos, o novo perfil de temperatura da estrutura modificada do transformador foi calculado por meio do MEF, substituindo-se os suportes de material magnético por novos suportes de aço inox, devidamente pintados e tratados para evitar a geração indesejada de $\mathrm{H}_{2}$. O novo perfil de temperatura é descrito na figura 23.

Figura 23 - Perfil de temperatura calculado por meio do MEF após o reparo.

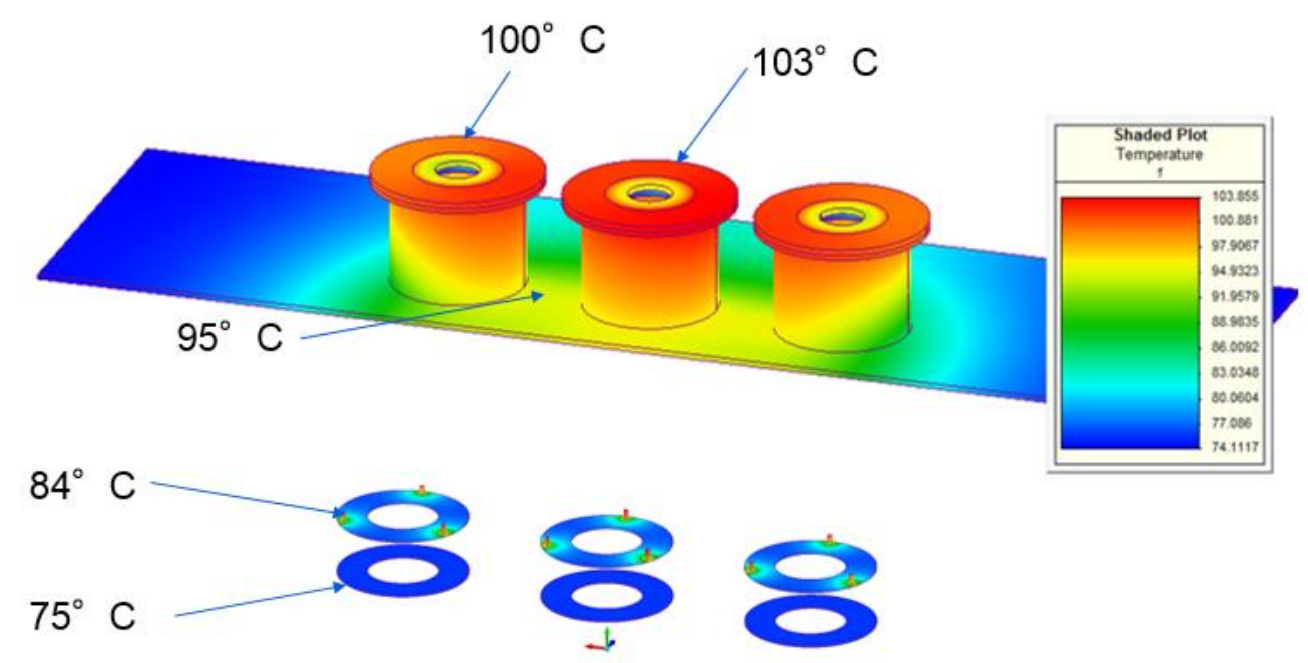

Fonte: Próprio Autor.

Comparando-se as temperaturas antes e depois da substituição dos suportes dos TCs, verifica-se que houve diminuição em torno de $20 \%$ da temperatura na parte superior dos canecos de suporte das buchas de baixa tensão e quase 50\% na estrutura do suporte dos TCs. 
Antes do reparo, o suporte dos TCs apresentavam temperaturas da ordem de $143{ }^{\circ} \mathrm{C}$ e após o reparo de $75^{\circ} \mathrm{C}$, como mostram as figuras 22 e 23 .

Novos testes elétricos de aquecimento e análise dos gases foram realizados para análise das alterações realizadas na estrutura do equipamento. A figura 24 mostra a análise termográfica por radiação infravermelha realizada após a substituição dos suportes dos TCs.

Figura 24 - Termovisão da parte superior do transformador após o reparo.
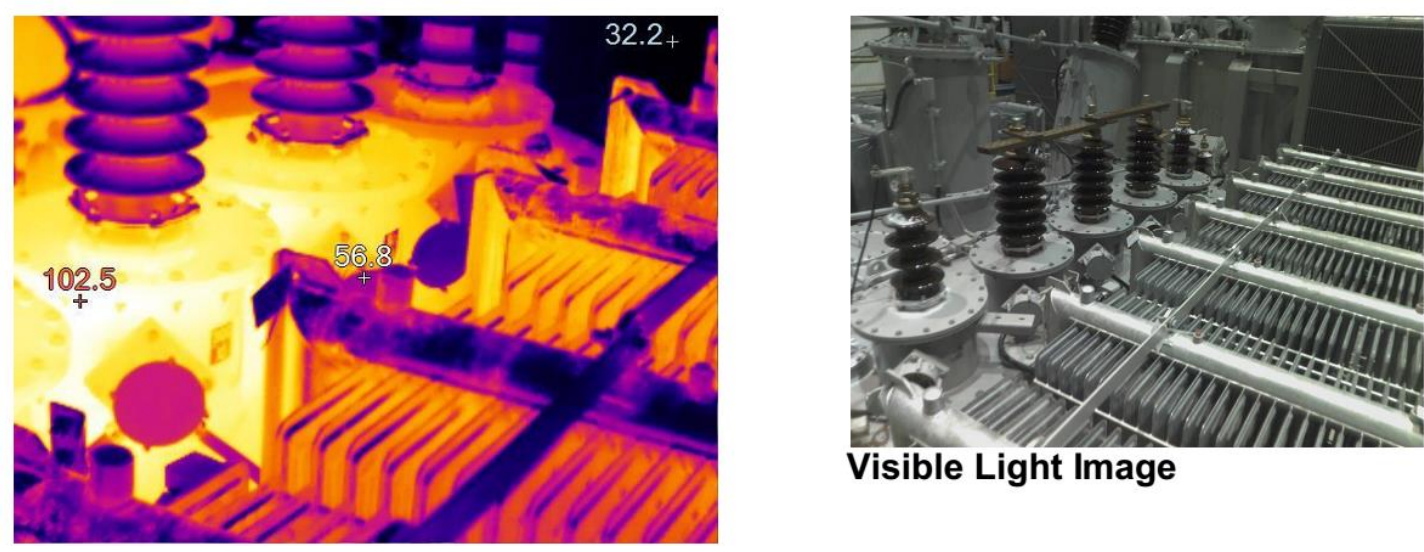

Visible Light Image

Fonte: Próprio Autor.

A termovisão mostrada na figura 24 indica $102,5^{\circ} \mathrm{C}$ na base da bucha de baixa tensão $\mathrm{X} 2$, enquanto os cálculos realizados por meio do $\mathrm{MEF}$, na figura 18 , mostram $103^{\circ} \mathrm{C}$ no mesmo ponto.

Visto que o transformador não apresentou falhas dielétricas, apenas o ensaio de aquecimento foi refeito para avaliação da temperatura e nova cromatografia. A tabela 5 mostra os resultados da cromatografia após a substituição dos suportes dos TCs.

Tabela 5 - Cromatografia após o reparo.

\begin{tabular}{|c|c|c|c|c|c|c|c|c|c|c|c|}
\hline Amostra & $\begin{array}{c}\text { Oxigênio } \\
\text { O2 }\end{array}$ & $\begin{array}{c}\text { Nitrogênio } \\
\text { N2 }\end{array}$ & $\begin{array}{c}\text { Diox. } \\
\text { Carbono } \\
\text { CO2 }\end{array}$ & $\begin{array}{c}\text { Hidrog. } \\
\text { H2 }\end{array}$ & $\begin{array}{c}\text { Monox. } \\
\text { Carbono }\end{array}$ & $\begin{array}{c}\text { Metano } \\
\text { CH4 }\end{array}$ & $\begin{array}{c}\text { Etano } \\
\text { C2H6 }\end{array}$ & $\begin{array}{c}\text { Etileno } \\
\text { C2H4 }\end{array}$ & $\begin{array}{c}\text { Acetileno } \\
\text { C2H2 }\end{array}$ & Observação & Tempo \\
\hline$\#$ & {$[\mathrm{ppm}]$} & {$[\mathrm{ppm}]$} & {$[\mathrm{ppm}]$} & {$[\mathrm{ppm}]$} & {$[\mathrm{ppm}]$} & {$[\mathrm{ppm}]$} & {$[\mathrm{ppm}]$} & {$[\mathrm{ppm}]$} & {$[\mathrm{ppm}]$} & & \\
\hline $\mathbf{5}$ & 1880 & 3475 & 14 & 3 & 1 & 0,1 & $\mathrm{nd}$ & $\mathrm{nd}$ & $\mathrm{nd}$ & Antes de todos ensaios & 0 \\
\hline $\mathbf{6}$ & 1501 & 3578 & 22 & 3 & 3 & 0,1 & $\mathrm{nd}$ & $\mathrm{nd}$ & $\mathrm{nd}$ & Após ensaios dielétricos & 6,5 \\
\hline $\mathbf{7}$ & 1489 & 3605 & 23 & 4 & 4 & 0,2 & $\mathrm{nd}$ & $\mathrm{nd}$ & $\mathrm{nd}$ & Após estabilização ONAN & 13 \\
\hline
\end{tabular}

Fonte: Próprio Autor.

De acordo com os novos resultados da cromatografia, não houve geração de gases resultantes de temperaturas excessivas, como o $\mathrm{C}_{2} \mathrm{H}_{6}$ e $\mathrm{C}_{2} \mathrm{H}_{4}$ e nem gases mais críticos como o $\mathrm{C}_{2} \mathrm{H}_{2}$, que de fato era esperado, pois o transformador não apresentou falhas na coordenação de 
isolamento. $\mathrm{O} \mathrm{H}_{2}$ se manteve em baixos níveis, visto que após o preenchimento do transformador e circulação do óleo durante a primeira série de testes, a concentração se mantém constante após a substituição ou desgaseificação do óleo, pois a reação com a tinta e verniz do tanque, radiadores e demais componentes ocorrera durante o primeiro preenchimento. Os traços de monóxido de carbono não indicam maiores problemas, pois não houve geração conjunta com outros gases combustíveis.

A tabela 6 descreve os valores referentes à evolução dos gases analisados na segunda cromatografia.

Tabela 6 - Evolução na formação de gases após o reparo.

\begin{tabular}{|c|c|c|c|c|c|c|c|c|}
\hline \multicolumn{7}{|c|}{ Geração de gases combustíveis após Ensaio de aquecimento } \\
\hline $\begin{array}{c}\text { Oxigênio } \\
\text { O2 }\end{array}$ & $\begin{array}{c}\text { Nitrogênio } \\
\text { N2 }\end{array}$ & $\begin{array}{c}\text { Diox. } \\
\text { Carbono } \\
\text { CO2 }\end{array}$ & $\begin{array}{c}\text { Hidrog. } \\
\text { H2 }\end{array}$ & $\begin{array}{c}\text { Monox. } \\
\text { Carbono }\end{array}$ & $\begin{array}{c}\text { Metano } \\
\text { CH4 }\end{array}$ & $\begin{array}{c}\text { Etano } \\
\text { C2H6 }\end{array}$ & $\begin{array}{c}\text { Etileno } \\
\text { C2H4 }\end{array}$ & $\begin{array}{c}\text { Acetileno } \\
\text { C2H2 }\end{array}$ \\
\hline$[\mathrm{ppm} / \mathrm{h}]$ & {$[\mathrm{ppm} / \mathrm{h}]$} & {$[\mathrm{ppm} / \mathrm{h}]$} & {$[\mathrm{ppm} / \mathrm{h}]$} & {$[\mathrm{ppm} / \mathrm{h}]$} & {$[\mathrm{ppm} / \mathrm{h}]$} & {$[\mathrm{ppm} / \mathrm{h}]$} & {$[\mathrm{ppm} / \mathrm{h}]$} & {$[\mathrm{ppm} / \mathrm{h}]$} \\
\hline $\mathrm{na}$ & $\mathrm{na}$ & $\mathrm{na}$ & 0,08 & 0,23 & $<0,008$ & $\mathrm{nd}$ & $\mathrm{nd}$ & $\mathrm{nd}$ \\
\hline
\end{tabular}

Fonte: Próprio Autor.

De acordo com a tabela 6, não houve evolução nos níveis de hidrogênio e $\mathrm{CH}_{4}$ após a substituição dos suportes dos TCs e do óleo do transformador. Dessa forma, pode-se concluir que o transformador está aprovado em todos os testes dielétricos e físico-químicos estabelecidos pelas normas técnicas. 


\section{Recomendações para especificações, projetos, operação e análise de transformadores}

Fundamentado nas análises e observações obtidas nos capítulos precedentes, é de relevância a inclusão de algumas recomendações para a especificação, projeto, operação e análise dos transformadores de potência no âmbito deste trabalho.

Considerando-se ainda que os transformadores são os equipamentos de maior valor agregado em uma subestação, apresentam números consideráveis de ocorrências de falhas em operação (BASTOS et al 2015), têm total influência na confiabilidade dos sistemas elétricos e que a indisponibilidade de energia elétrica gera altíssimos custos de multas às concessionárias de energia elétrica, as seguintes são pontuadas:

- É uma boa prática a análise crítica dos gases chave mesmo que suas concentrações estejam abaixo dos limites de norma. A não observância deste aspecto pode ocultar até mesmo uma falha grave a longo prazo;

- A utilização das ferramentas numéricas eficientes e precisas podem prever com antecedência e precisão eventuais problemas e até oportunidades de otimização dos equipamentos;

- Realização de cálculos e medições periódicas para aferição dos métodos de avaliação;

- Encoraja-se a aplicação do MEF no projeto dos transformadores com altas correntes para detecção e mitigação de problemas ainda na etapa de projeto, onde o custo de uma modificação é muito baixo comparado com o final do processo;

- A aplicação do MEF durante a elaboração das propostas técnicas e comerciais abrem portas para a realização de orçamentos mais precisos face à eventual necessidade da utilização de materiais mais onerosos;

- Deve haver uma investigação criteriosa antes de se decidir abrir uma unidade testada e aprovada nos ensaios dielétricos para investigação de eventual falha térmica;

- As amostras de gases devem ser retiradas com cuidado, bem identificadas e de preferência sempre utilizar o mesmo laboratório para análise. Ter certeza que o óleo retirado não é do OLTC e pertence ao transformador desejado;

- Implementação de rotinas adequadas de revisão e controle de projetos e processos de fabricação. 


\section{Conclusão}

Transformadores de potência do tipo GSU são equipamentos complexos, no que diz respeito aos itens da parte ativa, ou seja, métodos de isolação elétrica dos enrolamentos, entre espiras, enrolamentos e conexões contra partes aterradas como o tanques (isolação sólida e líquida), refrigeração forçada, técnicas de monitoramento elétrico e físico-químico do óleo, dentre outros itens. Uma vez que o equipamento é montado, ou seja, estão montados os enrolamentos, canecos, buchas e os tanques do transformador estão preenchidos com óleo, torna-se custoso e, na maioria dos casos, impraticável o reparo interno por meio de técnicas invasivas. Entende-se por métodos invasivos de reparo a reconstrução dos enrolamentos e substituição de centenas de milhares de litros de óleo no caso de grandes transformadores. Nesse contexto, este documento descreveu passo a passo um protocolo de teste e técnicas não invasivas para detecção e manutenção de defeitos em transformadores de potência.

Com base no método do gás chave, pode-se estimar a ocorrência de diversos tipos de falhas e de eventuais defeitos no interior dos transformadores, que vão desde a existência de falhas de projeto até falhas envolvendo grande quantidade de energia dissipada no óleo e consequentemente deterioração da isolação sólida e líquida do equipamento. No caso analisado, o método do gás chave determinou a existência de pontos quentes devido à existência de material diferente do que fora especificado no projeto. No entanto, o método de análise do óleo, por meio de cromatografia gasosa, não é suficientemente preciso para detectar a localização exata da falha ou a peça com defeito no interior do transformador. Dessa forma, como uma etapa complementar, foi proposta a análise termográfica por radiação infravermelha do transformador, que possibilita a detecção e medição da temperatura de superfícies sobreaquecidas externas e estimar os pontos quentes e faltosos no interior do equipamento.

O MEF e o método analítico, sendo esse último desenvolvido em função do campo magnético e potência dissipada nas proximidades dos pontos quentes, permite o cálculo do perfil de temperatura em partes internas e externas do transformador, bem como a temperatura máxima de sobreaquecimento nos pontos quentes. Ambos os métodos mostraram-se precisos quando comparados com medições realizadas diretamente nos pontos quentes detectados por meio das imagens termográficas.

A metodologia de detecção, localização e cálculo da temperatura dos pontos quentes mostra-se eficiente, uma vez que as características físicas e eletromagnéticas do equipamento são conhecidas. O conjunto de técnicas descreve um meio não invasivo para diagnóstico de 
falhas de projeto em transformadores de grande porte, abordando a detecção da formação de gases hidrocarbonetos e óxidos de carbono (relés de gases), identificação dos gases (cromatografia gasosa ou qualquer outra técnica de análise química do óleo) e localização exata dos pontos quentes e eventuais peças com defeito, fazendo uso de medições e métodos numéricos e analíticos para o cálculo da temperatura desses pontos.

A partir da metodologia proposta, aplicada a um transformador de potência real, foi possível detectar em ensaios preliminares (antes de ser entregue ao cliente) um defeito discreto, dificilmente detectável em campo no curto prazo ou sem a utilização de um relé de gás preciso. As concentrações medida de $\mathrm{H}_{2}$ e $\mathrm{CH}_{4}$ foram relativamente pequenas, podendo-se constatar alterações no óleo apenas a partir da evolução na formação de $\mathrm{H}_{2}$, segundo as descrições apresentadas pelo IEEE, ASTM e IEC. No entanto, a detecção dos pontos quentes, medições e cálculo da temperatura dos copos de suporte dos TCs foram possíveis em função da utilização do MEF e do método analítico desenvolvido ao longo do trabalho, em função do campo magnético e da potência dissipada nos flanges e canecos conectados às buchas de baixa tensão.

Por fim, vale observar que os suportes dos TCs foram trocados por suportes compostos por aço inox e que o óleo do transformador não foi substituído, passou novamente por processo de filtragem e desgaseficação, tal como descrito na planta da figura 17. 


\section{Referências}

ARANTES, J. G. Diagnóstico de falhas em transformadores de potência pela análise de gases dissolvidos em óleo isolante através de redes neurais. Dissertação de Mestrado, Universidade Federal de Itajubá, 2005.

ASTM D3612-90 (2002). Test methods for analysis of gases dissolved in electrical insulationg oil by gas chromatography.

BIRÓ, O. et al. (2009). Finite element method for nonlinear eddy current problems in power transformers. CIGRE International Colloquium on Transformer Research and Asset Management, Croácia.

BASTOS G., Marin M., Martins H., Asano R., Avaliação do desempenho de Transformadores de Potência e Reatores no Sistema Elétrico Brasileiro - XXII SNPTEE - Dez.2015.

CRETU, B.; SCHNEIDER, M. (2009). Coupled electromagnetic-thermal analysis for ABB power transformer. CIGRE International Colloquium on Transformer Research and Asset Management, Croácia.

CARDOSO, J. R. (2011). Engenharia Eletromagnética. 1ª ed., Rio de Janeiro: Elsevier.

CARDOSO, J. R. (2016). Electromagnetics through the finite element method. $1^{\mathrm{a}}$ ed., New York: CRC Press.

CALIL, W. et al. (2012). Development of a program for determination of the temperature at transformers copper bus bars by calculating their dimensionless numbers. CIGRE International Colloquium on Transformer Research and Asset Management, Croácia.

CALIL, W. (2009) Determinação de fator de correção para cálculo de perdas magnéticas em núcleos de transformadores de potência pelo método dos elementos finitos. Dissertação de mestrado EPUSP.

COMTRAFO INDUSTRIA DE TRANSFORMADORES ELÉTRICOS S.A. (2011). Transformadores a óleo: manual de instruções.

C.PERRIER , A. BEROUAL et al (2009) Experimental investigations on insulating liquids for power transformers: mineral, ester, and silicone oils, IEEE Electrical insulation magazine.

CRUZ, V. G. M. et al. (2015). Simulation of thermal decomposition of mineral insulating oil. Brazilian Journal of Chemical Engineering, v. 32, n. 3, p. 798-794.

DA SILVA, I. N. et al. (2001). Técnicas de sistemas inteligentes aplicadas na identificação do envelhecimento de transformadores. XVI Seminário Nacional de Produção e Transmissão de Energia Elétrica - SNPTEE, Curitiba, PR.

FERREIRA, D. A. P. Análise de falhas em transformadores de distribuição por metodologia forense. Dissertação de Mestrado, EESC/USP, São Carlos, 2013. 
FERNANDES P.O, Galdeano C.A, 2011. Disposição final por reciclagem do óleo mineral contaminado por bifenilas policloradas PCBs. XXI SNPTEE Seminário nacional de produção e transmissão de energia elétrica. Florianópolis Brasil.

FITZGERALD, A. E. et al. (2003). Electric Machinery. 6ª ed., McGraw-Hill.

GERTH, J. (2017). Dissolved Gas Analysis for Engineers, Power Transformer Testing Conf. ABB AB - Bad Honnef - Germany.

HAYT, W (2009). Engineering Eletromagnetics, Mc Graw Hill $6^{\text {th }}$ Edition.

HUANG YC, SUN HC, (2013) Dissolved gas analysis of mineral oil for power transformer fault diagnosis using fuzzy logic, IEEE Transactions on Dielectrics and Electrical Insulation.

HALSTEAD, W. D. (1973). A thermodynamic assessment of the formation of gaseous hydrocarbons in faulty transformers. Journal Inst. Petroleum, v. 59, p. 239-241.

IEEE Standard C57-104-2008 (2008). IEEE guide for the interpretation of gases generated in oil-immersed transformers.

IEC 60599 (1999). Mineral oil-impregnated electrical equipment in service: guide to the interpretation of dissolved and free gases analysis.

INCROPERA, F.P (2007). et al. Fundamentals of Heat and Mass Transfer, John Wiley \& Sons $70^{\text {th }} \mathrm{Ed}$.

JESZENSZKY, S. 1996. History of transformers. IEEE Power Eng Rev 16(12):9-12.

KARSAI, K. et al. (1987). Large Power Transformers. $1^{\text {a }}$ ed, New York: Elsevier.

LARS, E. L. et al. (2004). Aging of oil-impregnated paper in power transformers. IEEE Transactions on Power Delivery, v. 19, n. 1, p. 230-239.

MENDES, J.C (1987) Transformadores: Fundamentos, tecnologia, desempenho e aplicações. Literatura Técnica Asea Brown Boveri.

MARTINS, A.C et al (2014) Confiabilidade dos sistemas de preservação de óleo isolante. VII Workspot Internaciona sobre transformadores - Rio de Janeiro Brasil

NBR ISO9001, 2015. Sistema de gestão de qualidade - Requisitos. Norma ABNT NBR idêntica à ISO9001.

PREVOST, T. A. (2005). Thermally upgraded insulation in transformers. Electrical Insulation Conf. And Electrical Manufacturing Expo, EUA.

SOUZA, A. M.; CALIL, W. V. (2014). Hot spot control of structural parts due to high current leads in power transformers by means of the 3D-FEM. $3^{\text {rd }}$ CIGRE International Colloquium Transformer Research and Asset Management, Croácia. 
SOUZA, A. et al. (2016) Redução de falhas em transformadores de potência: desempenho térmico das saídas dos enrolamentos. VIII CIGRE International Workshop on Power Transformers, Equipment, Substation and Materials, Recife, PB.

UNITED STATES DEPARTMENT OF THE INTERIOR (2003). Transformer diagnostics: facilities instructions, Standards and techniques, v. 3-31.

VECHIO R.M et al (2009) Transformer design Principles $2^{\text {nd }}$ Edition CRC Press

WADHWA C.L (2007), High Voltage Engineering. $2^{\text {nd }}$ Edition New Age

ZIRBES, R. et al. (2005). Metodologias para avaliação e diagnóstico do estado de isolamentos de papel impregnado com óleo mineral. Revista Controle \& Automação, v. 16, n. 3, p. 318331. 